\title{
Performance assessment of a triple-frequency spaceborne cloud-precipitation radar concept using a global cloud-resolving model
}

\author{
J. Leinonen ${ }^{1}$, M. D. Lebsock ${ }^{1}$, S. Tanelli ${ }^{1}$, K. Suzuki ${ }^{1,3}$, H. Yashiro ${ }^{2}$, and Y. Miyamoto ${ }^{2}$ \\ ${ }^{1}$ Jet Propulsion Laboratory, California Institute of Technology, Pasadena, California, USA \\ ${ }^{2}$ RIKEN Advanced Institute for Computational Sciences, Kobe, Japan \\ ${ }^{3}$ Atmosphere and Ocean Research Institute, University of Tokyo, Kashiwa, Japan
}

Correspondence to: J. Leinonen (jussi.s.leinonen@jpl.nasa.gov)

Received: 24 March 2015 - Published in Atmos. Meas. Tech. Discuss.: 24 April 2015

Revised: 6 July 2015 - Accepted: 10 August 2015 - Published: 26 August 2015

\begin{abstract}
Multi-frequency radars offer enhanced detection of clouds and precipitation compared to single-frequency systems, and are able to make more accurate retrievals when several frequencies are available simultaneously. An evaluation of a spaceborne three-frequency Ku-/Ka-/W-band radar system is presented in this study, based on modeling radar reflectivities from the results of a global cloud-resolving model with a $875 \mathrm{~m}$ grid spacing. To produce the reflectivities, a scattering model has been developed for each of the hydrometeor types produced by the model, as well as for melting snow. The effects of attenuation and multiple scattering on the radar signal are modeled using a radiative transfer model, while nonuniform beam filling is reproduced with spatial averaging. The combined effects of these are then quantified both globally and in six localized case studies. Two different orbital scenarios using the same radar are compared. Overall, based on the results, it is expected that the proposed radar would detect a high-quality signal in most clouds and precipitation. The main exceptions are the thinnest clouds that are below the detection threshold of the W-band channel, and at the opposite end of the scale, heavy convective rainfall where a combination of attenuation, multiple scattering and nonuniform beam filling commonly cause significant deterioration of the signal; thus, while the latter can be generally detected, the quality of the retrievals is likely to be degraded.
\end{abstract}

\section{Introduction}

The processes governing the formation of precipitation from clouds are among the primary sources of uncertainty in the present understanding and future predictions of the Earth's climate system. The uncertainty stems, in large part, from the insufficient knowledge about the microphysical processes involved with the aerosol-cloud-precipitation interactions and their relative importance in the global context. In order to determine these quantitatively, global measurements are required.

As the majority of the Earth is outside of the reach of practical ground-based or airborne measurements, global coverage can be most conveniently achieved by remote sensing satellites. Cloud and precipitation observations from satellites are typically made with visible and infrared spectrometers, microwave radiometers, lidars and radars. Of these, radars are the only technology that can resolve the entire vertical profile of the clouds and precipitation, with the exception of the thinnest clouds. Previously, spaceborne cloud and precipitation radars have been launched on board the Tropical Rainfall Measurement Mission (TRMM) by the National Aeronautics and Space Administration (NASA) and the Japanese Aerospace Exploration Agency (JAXA) (Kummerow et al., 2000), on CloudSat by NASA (Stephens et al., 2008), and on the Global Precipitation Measurement (GPM) Core Observatory by NASA and JAXA (Hou et al., 2014). Additionally, the Earth Clouds, Aerosol and Radiation Explorer (EarthCARE), which includes a cloud radar, is currently being built by the European Space Agency and JAXA 
Table 1. Summary of approximate specifications of current and upcoming spaceborne radars, with comparison to the configuration examined in this study. The TRMM specifications are values after the 2001 orbital boost and before the exhaustion of propellant in 2014 . The footprint of the W-band channel at the $450 \mathrm{~km}$ configuration is limited by the resolution of the NICAM model.

\begin{tabular}{lcrrrl}
\hline Satellite & Frequency & $\begin{array}{r}\text { Approx. nominal } \\
\text { sensitivity }\end{array}$ & Footprint & $\begin{array}{r}\text { Range } \\
\text { resolution }\end{array}$ & Swath \\
\hline TRMM & $13.8 \mathrm{GHz}$ & $18 \mathrm{dBZ}$ & $5.0 \mathrm{~km}$ & $250 \mathrm{~m}$ & $215 \mathrm{~km}$ \\
CloudSat & $94.0 \mathrm{GHz}$ & $-30 \mathrm{dBZ}$ & $1.5 \mathrm{~km}$ & $500 \mathrm{~m}$ & Nadir \\
GPM (Ku band) & $13.6 \mathrm{GHz}$ & $18 \mathrm{dBZ}$ & $5.0 \mathrm{~km}$ & $250 \mathrm{~m}$ & $245 \mathrm{~km}$ \\
GPM (Ka band) & $35.6 \mathrm{GHz}$ & $12-15 \mathrm{dBZ}$ & $5.0 \mathrm{~km}$ & $250 / 500 \mathrm{~m}$ & $120 \mathrm{~km}$ \\
EarthCARE & $94.0 \mathrm{GHz}$ & $-36 \mathrm{dBZ}$ & $0.75 \mathrm{~km}$ & $400 \mathrm{~m}$ & Nadir \\
\hline This study: band (orbit altitude $)$ & & & & \\
Ku band $(450 \mathrm{~km})$ & $13.6 \mathrm{GHz}$ & $0 \mathrm{dBZ}$ & $4.0 \mathrm{~km}$ & $250 \mathrm{~m}$ & \\
Ku band $(817 \mathrm{~km})$ & & $5 \mathrm{dBZ}$ & $7.3 \mathrm{~km}$ & & \\
Ka band $(450 \mathrm{~km})$ & $35.6 \mathrm{GHz}$ & $-12 \mathrm{dBZ}$ & $1.4 \mathrm{~km}$ & $250 \mathrm{~m}$ & \\
Ka band $(817 \mathrm{~km})$ & & $-7 \mathrm{dBZ}$ & $2.5 \mathrm{~km}$ & & \\
W band $(450 \mathrm{~km})$ & $94.0 \mathrm{GHz}$ & $-35 \mathrm{dBZ}$ & $0.85 \mathrm{~km}$ & $250 \mathrm{~m}$ & \\
W band $(817 \mathrm{~km})$ & & $-30 \mathrm{dBZ}$ & $1.2 \mathrm{~km}$ & & \\
\hline
\end{tabular}

(Hélière et al., 2007). Table 1 summarizes the capabilities of the radars on these satellites.

So far, spaceborne radar missions targeting the cloudprecipitation cycle have focused on measuring only one of these components. This has been due to the technological limitations of the radars: lower frequency radars (at the $\mathrm{Ku}$ band, around $13 \mathrm{GHz}$ ) have not been possible to build at high enough sensitivity for cloud measurements, and these have thus been limited to measuring precipitation. Meanwhile, at higher frequencies, such as with the $94 \mathrm{GHz}$ (W-band) radar on CloudSat, the sensitivity has been sufficient for clouds, but the radiation is attenuated too strongly to make measurements in heavy precipitation. Their signal also suffers from multiple scattering and saturates at high reflectivities due to non-Rayleigh scattering effects. Nevertheless, achieving a process-level understanding of clouds and precipitation requires simultaneous measurements of both of them.

Coverage throughout the vertical profile of hydrometeors can be achieved using several channels at different frequencies. A further benefit of simultaneous measurements at multiple frequencies is that they can be used to constrain the properties of the target better, as is already done with the dual-frequency radar of the GPM core satellite. Threefrequency measurements also appear promising for better constraining the properties of icy precipitation (Kneifel et al., 2011; Leinonen et al., 2012; Kulie et al., 2014; Leinonen and Moisseev, 2015). The Aerosol-Cloud-Ecosystem (ACE) mission concept recommended in the 2007 decadal survey (National Research Council, 2007) is designed to study both clouds and precipitation using a $\mathrm{Ka} / \mathrm{W}$-band dual-frequency radar with a considerably higher sensitivity than that of the GPM Core Observatory. There is a growing consensus in the ACE radar community that an ideal radar configuration would have three frequencies to provide global cloud and precipitation profiling capability on a single platform.

While the advantages and disadvantages of specific choices for the three frequencies can be debated at length, here we adopt the choice that is mainly defined by the value of existing data record established so far by the TRMM, CloudSat and GPM radars: Ku, Ka and $\mathrm{W}$ bands. For the Ka- and W-band channels, we adopt a performance based on a notional configuration that would satisfy the ACE requirements if placed on a platform orbiting at $450 \mathrm{~km}$ altitude. For the Ku-band channel, we use parameters that mimic the resolution of the TRMM Precipitation Radar, while improving its sensitivity by almost $15 \mathrm{~dB}$ to capture also light precipitation. All the high level performance parameters assumed in this work are listed in Table 1. The performance is evaluated at two low Earth orbit scenarios: at 450 and $817 \mathrm{~km}$ altitudes. The latter is motivated by possible constellation opportunities with the MetOp satellites, whereas the former optimizes spatial resolution and sensitivity while avoiding problematic atmospheric drag. Both scenarios are assumed to use the same radar hardware, based on a $2.5 \mathrm{~m}$ radar antenna that is a candidate for the ACE mission (Tanelli et al., 2009), and thus the higher orbit has a lower sensitivity and a larger radar footprint. A single antenna is used for all bands because the ACE science working group expressed preference for maximum sensitivity over matched beams. While this leads to the different bands not having matched beams, approximate beam matching can be achieved in data postprocessing through spatial averaging.

Prior studies have used cloud-resolving or large eddy simulation models, which explicitly resolve clouds, to simulate satellite observations. While highly useful, these studies lack global context. In this study, we globally estimate 
the performance of the triple-frequency cloud and precipitation radar concept. The radar measurements are modeled from a very high-resolution global atmospheric model, with a grid cell roughly the same size as the smallest radar footprint of $850 \mathrm{~m}$. This allows us to determine the global-scale statistics of radar observations at the actual resolution of the radar, rather than being constrained by the model resolution. Thus, we are able to estimate the effects of attenuation, multiple scattering and nonuniform beam filling (NUBF) on the radar signal. We show that the proposed triple-frequency combination is able to measure at least one frequency in almost all conditions, and can thus observe the entire cloud-precipitation process. It can also make dual- or triple-frequency measurements of a large fraction of the observed precipitation, improving its ability to quantify cloud and precipitation microphysical properties.

\section{Modeling}

\subsection{NICAM $875 \mathrm{~m}$ global simulation}

Simulation of high resolution satellite observations from typical global models requires an assumption regarding the subgrid scale distribution of the geophysical parameters, such as that employed by the Cloud Feedback Model Intercomparison Project Observation Simulator Package (COSP; BodasSalcedo et al., 2011) to estimate the sub-grid variability. Furthermore, this approach ignores spatial coherence, making simulation of nonuniform beam filling (NUBF) impossible. The emergence of global cloud-resolving models with spatial resolution better than that of the observations allows for credible simulation of satellite observables, including sub-fieldof-view effects, on a global scale. One leading example of such a model is the Nonhydrostatic Icosahedral Atmospheric Model (NICAM) (Tomita and Satoh, 2004; Satoh et al., 2008, 2014). Its ability to run at extremely high resolution allows NICAM to simulate deep convection and mesoscale circulation directly. The spatial scales of these phenomena are smaller than the resolution of most other global models, which require parameterization.

The $875 \mathrm{~m}$ NICAM run used in this study (Miyamoto et al., 2013) models the cloud and precipitation microphysics by dividing the hydrometeors into five distinct types: rain, snow, graupel, cloud water and cloud ice. A single-moment microphysics scheme is used for each class; a bin microphysics scheme is under development for NICAM, but its computational cost would be prohibitive in the $875 \mathrm{~m}$ resolution run, where the computational resource requirements are extremely high even for the single-moment scheme. A detailed description of how the hydrometeor types evolve and interact is given by Tomita (2008). The main difference between that scheme and the one adopted in the $875 \mathrm{~m}$ run is that the Tomita (2008) scheme varies the constant cloud droplet number concentration between oceanic and land ar- eas, while the $875 \mathrm{~m}$ run specifies it as $50 \mathrm{~cm}^{-1}$ over both ocean and land.

\subsection{Single-scattering models}

\subsubsection{Overview}

To compute the radar observables from the NICAM model data, we developed a microwave single-scattering model for each of the five hydrometeor types. The overall procedure is the same for each type: the single-scattering properties are first computed for a range of particle sizes; these are then integrated over a size distribution to yield the size-averaged backscattering cross section $\sigma_{\text {bsc }}$, scattering cross section $\sigma_{\text {sca }}$, extinction cross section $\sigma_{\text {ext }}$ and the asymmetry parameter $g$ (for definitions, see van de Hulst, 1957). These quantities are needed as inputs to the multiple scattering code. In the absence of attenuation or multiple scattering, one obtains the equivalent radar reflectivity $Z_{\mathrm{e}}$ from $\sigma_{\mathrm{bsc}}$ as

$Z_{\mathrm{e}}=\frac{\lambda^{4}}{\pi^{5}\left|K_{\mathrm{w}}\right|^{2}} \int_{D_{\min }}^{D_{\max }} \sigma_{\mathrm{bsc}}(D) N(D) \mathrm{d} D$,

where $D$ is the particle diameter, $\lambda$ is the wavelength, $N(D)$ is the particle size distribution and $K_{\mathrm{w}}=\left(n_{\mathrm{w}}^{2}-1\right) /\left(n_{\mathrm{w}}^{2}+2\right)$ for the complex refractive index of water $n_{\mathrm{w}}$ at the given frequency and temperature. The reflectivity in logarithmic dBZ units is given by

$Z=\log _{10} \frac{Z_{\mathrm{e}}}{Z_{0}}$,

where $Z_{0}=1 \mathrm{~mm}^{6} \mathrm{~m}^{-3}$. The reflectivity that is actually observed by the radar is further affected by attenuation, multiple scattering and nonuniform beam filling; we discuss these in Sects. 2.3 and 2.4.

When formulating the single-scattering models, our overall goal was to be as consistent as possible with the assumptions made in the NICAM microphysics model. However, in some cases the microphysics model makes assumptions about the hydrometeors that, while reasonable for modeling microphysics, will cause errors in the scattering properties, which are disproportionately affected by the largest particles in the size distribution. In these cases, it was necessary to make additional assumptions about the particle size. Such assumptions were always formulated such that they were consistent with the water content given by the model. Additionally, the NICAM microphysics model does not include melting snow, which is a significant source of attenuation and causes a characteristic bright band of reflectivity near the $0{ }^{\circ} \mathrm{C}$ isotherm. To reproduce these features, melting snow was added in areas where raindrops coexisted with snow or graupel.

The procedures used to model the different hydrometeor types are detailed below in Sects. 2.2.2-2.2.7. For all types, 
the radar beam was assumed to be vertical. For water and ice, we adopted the refractive indices of Ray (1972) and Warren and Brandt (2008), respectively, assuming a $0^{\circ} \mathrm{C}$ temperature for this purpose in order to reduce the computational burden; the impact of this is minor compared to that of the hydrometeor amount and distribution. As an exception to the above, the snow and cloud ice scattering properties are derived from other authors' databases, and thus use the refractive indices that those authors adopted.

\subsubsection{Rain}

The single scattering properties of raindrops were computed with a T-matrix scattering code (Mishchenko and Travis, 1998; Leinonen, 2014). Raindrops were modeled as oblate spheroids of water with the size-dependent axis ratios given by Thurai et al. (2009). The raindrops were assumed to be partially aligned by aerodynamical effects, resulting in the angle between the symmetry axis and the vertical axis being distributed normally with a mean of $0^{\circ}$ and SD of $7^{\circ}$.

The NICAM microphysical scheme uses the MarshallPalmer exponential form of the particle size distribution (PSD)

$N_{\mathrm{r}}(D)=N_{0, \mathrm{r}} \exp \left(-\Lambda_{\mathrm{r}} D\right)$

with the intercept parameter $N_{0, \mathrm{r}}=8 \times 10^{6} \mathrm{~m}^{-4}$. NICAM outputs the rainwater content $q_{\mathrm{r}, \mathrm{s}}$, defined as the mass of rainwater contained in a unit mass of air. Given $q_{\mathrm{r}, \mathrm{s}}$, and requiring conservation of mass, the slope parameter $\Lambda$ can be obtained as (Tomita, 2008)

$\Lambda_{\mathrm{r}}=\left(\frac{\pi \rho_{\mathrm{r}} N_{0, \mathrm{r}}}{\rho_{\mathrm{air}} q_{\mathrm{r}, \mathrm{s}}}\right)^{1 / 4}$

where $\rho_{\mathrm{r}}=1000 \mathrm{~kg} \mathrm{~m}^{-3}$ is the density of water and $\rho_{\text {air }}$ is the density of air, which can be computed from the model output. This form of the PSD was adopted for the single-scattering model; the scattering properties of the raindrop ensemble can be computed by integrating them over the PSD of Eq. (3). The minimum and maximum hydrometeor size for rain were chosen as 0 and $8 \mathrm{~mm}$, respectively.

\subsubsection{Snow}

NICAM models the microphysics of snowflakes using the same Marshall-Palmer PSD as that for the raindrops, with intercept parameter $N_{0, \mathrm{~s}}=3 \times 10^{6} \mathrm{~m}^{-4}$ and constant snowflake density of $\rho_{\mathrm{s}}=100 \mathrm{~kg} \mathrm{~m}^{-3}$. However, the mass of snowflakes $m_{\mathrm{s}}$ is typically given as a power-law fit

$m_{\mathrm{s}}=\alpha_{\mathrm{s}} D_{\mathrm{s}}^{\beta_{\mathrm{s}}}$

where the constants $\alpha$ and $\beta$ are usually determined experimentally. Additionally, studies over the recent years have shown that the use of homogeneous spherical and spheroidal shapes to model radar observations of snowflakes can lead to an underestimation of the backscattering cross section by up to an order of magnitude (e.g., Petty and Huang, 2010; Tyynelä et al., 2011) compared to those derived from models with detailed snowflake structure.

In order to use more realistic snowflake scattering properties, we obtained them from the database published by Nowell et al. (2013), which was generated by using the discrete dipole approximation (DDA) to compute the scattered radiation from aggregates of bullet rosettes. There are three different types of snowflakes in this database: aggregates comprised of either 200 or $400 \mu \mathrm{m}$ diameter rosettes, or a combination of the two. The combination type was selected for this analysis, as variable snow crystal size is probably the more realistic choice. We used regression analysis to determine the coefficients of Eq. (5) for these aggregates as $\alpha_{\mathrm{s}}=0.353$ and $\beta_{\mathrm{s}}=2.293$ (with $m_{\mathrm{s}}$ and $D_{\mathrm{s}}$ in SI units).

Because $\beta \neq 3$, the snow density is variable, which is incompatible with the assumptions of the NICAM microphysics scheme. Directly using the PSD given by Eq. (3) for the variable-density snowflakes would violate the conservation of mass. Therefore, to resolve this inconsistency, the PSD must be modified to accommodate for this, while simultaneously retaining as much consistency as possible with the model assumptions. We assumed that the snowflake mass distribution given by the model remains valid, because the snowflake mass $m_{\mathrm{s}}$ is the most important factor in determining its scattering properties, and because this approach naturally conserves the total snow water content. With this assumption, the PSD for the variable density snowflakes, $N_{\mathrm{s}}$, becomes

$N_{\mathrm{s}}(D)=N_{0, \mathrm{~s}} \exp \left(-C \Lambda_{\mathrm{s}} D^{\beta_{s} / 3}\right) \frac{C \beta_{s}}{3} D^{\beta_{s} / 3-1}$,
$C=\left(\frac{6 \alpha_{s}}{\pi \rho_{\mathrm{s}}}\right)^{1 / 3}$,

where $\Lambda_{\mathrm{S}}$ is the slope parameter obtained using the constant value of $\rho_{\mathrm{s}}$ as

$\Lambda_{\mathrm{s}}=\left(\frac{\pi \rho_{\mathrm{s}} N_{0, \mathrm{~s}}}{\rho_{\mathrm{air}} q_{\mathrm{s}}}\right)^{1 / 4}$.

The derivation of Eqs. (6) and (7) is given in the Appendix.

\subsubsection{Graupel}

Graupel results from snowflakes being rimed by supercooled water droplets. This has an effect of smoothening the details of snowflakes. For this reason, and due to the lack of availability of graupel particle databases when the study was conducted, we modeled the graupel scattering properties with the T-matrix method. The graupel density was set to the NICAM assumption of $\rho_{\mathrm{g}}=400 \mathrm{~kg} \mathrm{~m}^{-3}$ and the axis ratio to a constant value of 0.8 . The canting angle was assumed to be normally distributed with a mean of $0^{\circ}$ and a SD of $20^{\circ}$. 
The density of graupel particles generally does not vary much with size, and thus the adjustment to the PSD described for snow in the previous section was unnecessary. Thus, we adopted the PSD formulation used for graupel by NICAM, the equivalent of Eq. (3) with graupel intercept parameter $N_{0, \mathrm{~g}}=4 \times 10^{6} \mathrm{~m}^{-4}$.

\subsubsection{Cloud water}

Cloud water droplets are small compared to radar wavelengths, and very close to spherical in shape. Thus, the scattering from these can be reliably modeled with the Rayleigh approximation (van de Hulst, 1957). Unlike with rain, snow and graupel, the NICAM microphysics scheme does not include any explicit assumptions about the cloud droplet PSD; it only specifies a constant droplet number concentration of $N_{\mathrm{t}, \mathrm{c}}=50 \mathrm{~cm}^{-3}=5 \times 10^{7} \mathrm{~m}^{-3}$. Because of the $D^{6}$ dependence of the scattering and backscattering cross sections, the scattering results are disproportionately affected by the large droplets, and thus an assumption must be made about the type of PSD. Following Miles et al. (2000, their Eq. 2 and Table 3), we adopted a modified gamma distribution

$N_{\mathrm{c}}(D)=\frac{N_{\mathrm{t}, \mathrm{c}}}{\Gamma\left(v_{\mathrm{c}}\right)}\left(\frac{D}{D_{n}}\right)^{\nu_{\mathrm{c}}-1} \frac{1}{D_{n}} \exp \left(-\frac{D}{D_{n}}\right)$,

with shape parameter $v_{\mathrm{c}}=8.6$. Given $v_{\mathrm{c}}$, the cloud water content $q_{\mathrm{c}}$, and the droplet density $\rho_{\mathrm{c}}=1000 \mathrm{~kg} \mathrm{~m}^{-3}$, one can integrate $D^{6} N(D)$ using Eq. (9) and solve for the scaling diameter as

$D_{n}=\left(\frac{6 q_{\mathrm{c}}}{\pi N_{\mathrm{t}, \mathrm{c}}} \frac{\rho_{\mathrm{air}}}{\rho_{\mathrm{c}}} \frac{\Gamma\left(v_{\mathrm{c}}\right)}{\Gamma\left(v_{\mathrm{c}}+3\right)}\right)^{1 / 2}$.

The radar reflectivity $Z$ and the size-integrated scattering, backscattering and absorption cross sections can then be solved analytically as

$Z=\int_{0}^{\infty} D^{6} N_{\mathrm{c}}(D) \mathrm{d} D=N_{\mathrm{t}, \mathrm{c}} D_{n}^{6} \frac{\Gamma\left(v_{\mathrm{c}}+6\right)}{\Gamma\left(v_{\mathrm{c}}\right)}$,

$\sigma_{\mathrm{bsc}}=\frac{\pi^{5}|K|^{2}}{\lambda^{4}} Z$,

$\sigma_{\text {sca }}=\frac{2 \pi^{5}|K|^{2}}{3 \lambda^{4}} Z$,

$\sigma_{\mathrm{abs}}=N_{\mathrm{t}, \mathrm{c}} D_{n}^{3} \frac{\pi^{2}}{\lambda} \frac{\Gamma\left(v_{\mathrm{c}}+3\right)}{\Gamma\left(v_{\mathrm{c}}\right)} \operatorname{Im}[K]$.

\subsubsection{Cloud ice}

The estimation of realistic scattering properties from the ice clouds poses similar problems as the cloud water as the NICAM model makes no underlying assumptions about the PSD; furthermore, it involves the complex shapes of atmospheric ice particles. For the scattering properties, we used the database of Liu (2008), which contains the cross sections of various ice crystal types and sizes computed using DDA. In order to contain the complexity of the problem, the bullet rosettes were used to represent all snow crystal types. This choice is consistent with our aggregate snowflakes; the Liu (2008) rosettes have also been found to produce reasonable results in retrieval algorithms (Haynes et al., 2009) and to perform fairly in the simulation of passive microwave radiances used in data assimilation into numerical weather prediction models (Geer and Baordo, 2014).

The ice particle size distribution was derived from the empirical fits of Heymsfield et al. (2013); the composite formulas of their Table 3 are used here. They give the PSD in the gamma form

$N_{i}(D)=N_{0, i} D_{\mathrm{i}}^{\mu} \exp \left(-\Lambda_{\mathrm{i}} D\right)$,

with the shape parameter $\mu_{\mathrm{i}}$ given as a function of the slope parameter $\Lambda_{\mathrm{i}}$ as

$\mu=0.22 \Lambda_{\mathrm{i}}^{0.308}-3$,

the total number concentration $N_{\mathrm{t}, i}$ as a function of temperature $T$ as

$N_{\mathrm{t}, i}=\left\{\begin{array}{ll}2.7 \times 10^{4} & T \leq-60^{\circ} \mathrm{C} \\ 3.304 \times 10^{3} \exp (-0.04607 T) & T>-60^{\circ} \mathrm{C}\end{array}\right.$,

and the maximum diameter $D_{\max }$ as

$D_{\max }=\left\{\begin{array}{ll}1.35 \times 10^{3} \Lambda_{\mathrm{i}}^{-0.64} & T \leq-60^{\circ} \mathrm{C} \\ 1.51 \times 10^{4} \Lambda_{\mathrm{i}}^{-0.77} & T>-60^{\circ} \mathrm{C}\end{array}\right.$,

where $T$ is in degrees Celsius, and $N_{\mathrm{t}, i}, \Lambda_{\mathrm{i}}$ and $D_{\max }$ are given in SI units (hence the difference to the original formulas, which are in cgs units).

Given $T$ and cloud ice water content $q_{\mathrm{i}}$ from the model, as well as the empirical formulas of Eqs. (16), (17) and (18), one can solve for $N_{0, i}$ and $\Lambda_{\mathrm{i}}$ from the identities

$$
\begin{aligned}
& N_{\mathrm{t}, i}=\int_{0}^{D_{\max }} N_{i}(D) \mathrm{d} D=N_{0, i} \int_{0}^{D_{\max }} D_{\mathrm{i}}^{\mu} \exp \left(-\Lambda_{\mathrm{i}} D\right) \mathrm{d} D, \\
& q_{\mathrm{i}}=\rho_{\text {air }}^{-1} \int_{0}^{D_{\max }} \alpha_{\mathrm{i}} D_{\mathrm{i}}^{\beta} N_{\mathrm{i}}(D) \mathrm{d} D .
\end{aligned}
$$

The system of equations given by Eqs. (16)-(20) is not analytically solvable, but thanks to the monotonicity of the functions, it can be easily solved numerically. As with snow, the coefficients $\alpha_{\mathrm{i}}=0.166$ and $\beta_{\mathrm{i}}=2.249$ were derived using regression analysis from the Liu (2008) data set.

\subsubsection{Melting snow}

The NICAM microphysics scheme does not treat melting snow and graupel explicitly; rather, it converts these hydrometeor types to rain at temperatures above $0{ }^{\circ} \mathrm{C}$. The melting 
layer is, however, characterized by the bright band of high reflectivity as well as by strong attenuation, and is therefore important in radar observations. Thus, we simulated the melting layer by reassigning parts of the snow, graupel and rain water contents to "melting snow" and "melting graupel" classes in regions where snow or graupel coexisted with rain.

The approach we have adopted is motivated by the considerations of Haynes et al. (2009). Firstly, in regions where rain coexists with both snow and graupel, we use a bulk approximation to partition the rainwater content $q_{\mathrm{r}, \mathrm{s}}$ into the rain originating from melted snow $\left(q_{\mathrm{r}, \mathrm{s}}\right)$ and that originating from melted graupel $\left(q_{\mathrm{r}, \mathrm{g}}\right)$ :

$q_{\mathrm{r}, \mathrm{s}}=q_{\mathrm{r}} \frac{q_{\mathrm{s}}}{q_{\mathrm{s}}+q_{\mathrm{g}}}$,

$q_{\mathrm{r}, \mathrm{g}}=q_{\mathrm{r}}-q_{\mathrm{r}, \mathrm{s}}$.

These two types are handled separately but identically except for microphysical constants, and the results are eventually summed together. Thus, we only present the melting procedure for snow below; the treatment of graupel merely substitutes the subscript "s" with "g".

For the balance of dry snow, melting snow and raindrops originating from snowflakes, conservation of mass gives

$q_{\mathrm{r}, \mathrm{e}}+q_{\mathrm{m}, \mathrm{e}}+q_{\mathrm{s}, \mathrm{e}}=q_{\mathrm{r}, \mathrm{s}}+q_{\mathrm{s}}$,

where we have introduced the new hydrometeor class of melting snow, denoted by the subscript " $m$ "; the subscript "e" denotes the effective water content in the various classes after we have allocated part of the snow and rain water contents to the melting snowflakes. We use $q_{\mathrm{m}, \mathrm{e}}$ to represent melting, mixed-phase snowflakes; $q_{\mathrm{s}, \mathrm{e}}$ for those snowflakes that do not yet exhibit appreciable amounts of melting; and $q_{\mathrm{r}, \mathrm{e}}$ for snowflakes that have melted completely and collapsed into raindrops. These are determined as a function of the melted fraction

$f=\frac{q_{\mathrm{r}, \mathrm{s}}}{q_{\mathrm{r}, \mathrm{s}}+q_{\mathrm{s}}}$.

In order to reproduce a plausible melting profile, one simple approach is for melting snowflakes to appear gradually at first, followed by all snowflakes melting simultaneously, and finally to have melting snow mixed with completely melted raindrops. We use the following continuous, piecewise linear equations to determine the effective water contents:

$$
\begin{aligned}
& q_{\mathrm{s}, \mathrm{e}}=q_{\mathrm{r}, \mathrm{s}}+q_{\mathrm{s}}-q_{\mathrm{m}, \mathrm{e}} \\
& \left.\begin{array}{l}
q_{\mathrm{m}, \mathrm{e}}=\frac{f}{f_{\mathrm{s}}}\left(q_{\mathrm{r}, \mathrm{s}}+q_{\mathrm{s}}\right) \\
q_{\mathrm{r}, \mathrm{e}}=0
\end{array}\right\} \quad f<f_{\mathrm{s}} \\
& q_{\mathrm{s}, \mathrm{e}}=0 \\
& \left.q_{\mathrm{m}, \mathrm{e}}=q_{\mathrm{r}, \mathrm{s}}+q_{\mathrm{s}}\right\} \quad f_{\mathrm{s}} \leq f<f_{\mathrm{r}}, \\
& q_{\mathrm{r}, \mathrm{e}}=0 \quad \\
& q_{\mathrm{s}, \mathrm{e}}=0 \\
& \left.q_{\mathrm{m}, \mathrm{e}}=q_{\mathrm{r}, \mathrm{s}}+q_{\mathrm{s}}-q_{\mathrm{r}, \mathrm{e}}\right\} \quad f_{\mathrm{r}} \leq f \\
& \left.q_{\mathrm{r}, \mathrm{e}}=\frac{f-f_{\mathrm{r}}}{1-f_{\mathrm{r}}}\left(q_{\mathrm{r}, \mathrm{s}}+q_{\mathrm{s}}\right)\right\}
\end{aligned}
$$

with the threshold values set to $f_{\mathrm{s}}=0.25$ and $f_{\mathrm{r}}=0.5$.

The scattering corresponding to $q_{\mathrm{s}, \mathrm{e}}$ and $q_{\mathrm{r}, \mathrm{e}}$ is modeled normally, as described in Sects. 2.2.2 and 2.2.3. For the modeling of melting snow, we adopted the Model 5 proposed by Fabry and Szyrmer (1999), which they found optimal among the spherical models they tested. In this model, melting snowflakes are represented by spheres of two homogeneous layers, in both of which the effective refractive index is computed using the Maxwell-Garnett approximation. The two layers differ in density and also in the configuration of inclusions and matrices used in computing the effective medium approximation of the air-ice-water mixture. The densities and the radii of the two layers vary as a function of the melting fraction $f$, which we assume to be equal for all snowflakes. Thus, the snowflakes transition from pure snow (ice-air mixture) spheres at $f=0$ to pure water drops at $f=1$. Although spherical models of snowflakes are known to exhibit much weaker backscattering than the equivalent detailed snowflake models, we avoid a discontinuity in reflectivity by gradually transforming ice-only snowflakes into melting ones, as per Eq. (25).

The PSD of the melting snowflakes is defined in terms of the PSD of the equivalent unmelted snowflakes. That is, for each unmelted snowflake diameter $D_{\mathrm{s}}$, we determine the equivalent-mass melted diameter $D_{\mathrm{m}}$, which depends on the melting fraction $f$, according to the assumptions of the Fabry and Szyrmer (1999) model. The scattering properties are then computed, using a two-layer Mie approximation, for spheres of size $D_{\mathrm{m}}$, but the PSD integration is carried out over $D_{\mathrm{s}}$. This means that, similar to the approach used in Sect. 2.2.3, the mass distributions of dry and melting snow are equal. Although we neglect the rain PSD given by the melting model in favor of that output by NICAM, there is again no discontinuity as the pure, ice-free raindrops are introduced gradually at $f>f_{\mathrm{r}}$.

\subsection{Attenuation and multiple scattering}

In order to simulate realistic radar reflectivity profiles, the attenuation and multiple scattering effects on the radar signal need to be considered. Attenuation can reduce or completely block the radar signal even from heavy precipitation lower in the atmosphere, especially at the $\mathrm{W}$ band given that attenuation increases with frequency. Multiple scattering, while often ignored in radar retrievals, has also been shown to be often relevant with spaceborne radar configurations (Battaglia et al., 2010, 2015) and is necessary to consider in W-band rain retrievals (Lebsock and L'Ecuyer, 2011).

We simulated these effects using the one-dimensional time-dependent two-stream (TDTS) radiative transfer code by Hogan and Battaglia (2008). The TDTS code was run separately for every column in the data using a $100 \mathrm{~m}$ vertical resolution. While a full three-dimensional simulation (e.g., Battaglia and Tanelli, 2011) would have been more realistic for simulating multiple scattering effects, the running time 
of such models would have been prohibitive given the size of our data set.

\subsection{Nonuniform beam filling}

Due to the nonzero width of the antenna beam, a radar produces an image less detailed than the features that are observed by it. The $875 \mathrm{~m}$ grid size of the NICAM model sets the lower limit for the resolution, but if the horizontal extent of the radar footprint is of the same size or larger than that, this blurring can be simulated by convolving the original data with the antenna pattern. The same type of averaging can be performed in the vertical direction by convolving with the radar pulse shape.

As we simulated the reflectivity from the global model grid, we did not assume any particular orbit for the satellite, and thus we cannot differentiate between along-track and across-track antenna patterns. Therefore, we assumed a Gaussian antenna pattern where the full width at half maximum (FWHM) was the average of the along-track and crosstrack widths, accounting for both the antenna beam width and along-track averaging caused by the motion of the spacecraft during the integration time. For the vertical averaging, the pulse shape was assumed to be a normalized box function.

An example of radar reflectivities generated with the methods presented in this section is shown in Fig. 1. This figure displays the vertical cross section of the simulated reflectivity for the $450 \mathrm{~km}$ orbit in the tropical cyclone case referred to as CYC in Sect. 5; only the points above the minimum detectable signal are shown. The capability of the $\mathrm{W}$ band to detect thin clouds is clearly demonstrated in that it is the only band able to detect the clouds above the cyclone eye. Meanwhile, attenuation of the Ka and $\mathrm{W}$ bands is apparent in the bottom few kilometers of the profile. The meltinglayer bright band also weakens as the frequency increases, in agreement with observations. By comparing the $\mathrm{Ku}-$ and W-band images, some blurring of the sharpest features can also be seen at the Ku band; this is due to the wider footprint at that frequency.

\section{Validation}

In order to examine how well the combination of NICAM and our scattering model performs, we compared modeled and measured radar reflectivity for the CloudSat and GPM configurations. The scattering model was configured according to the specifications of those satellites (as per Table 1). The model output in our data represents the situation on 25 August 2012, but due to the CloudSat battery anomaly in April 2011, the satellite was only collecting daytime data at that time. In order to avoid bias due to the diurnal cycle, we instead sampled the CloudSat data from 10 August 2010 to 9 September 2010. Likewise, GPM was not yet in orbit in 2012, so we used the period of 10 August 2014-9 Septem-

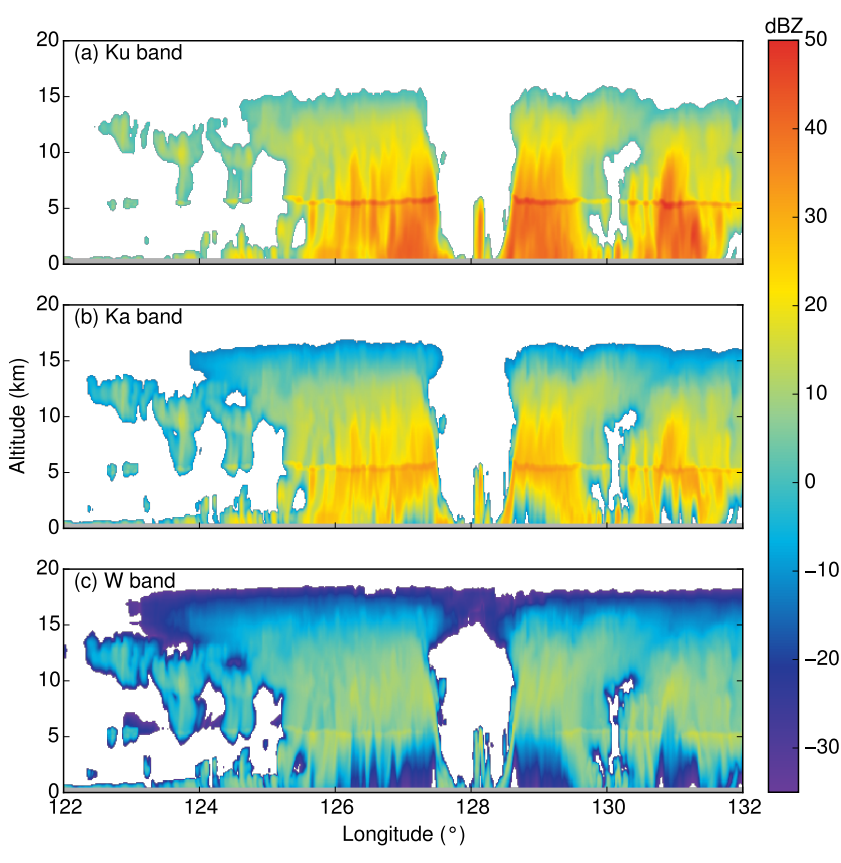

Figure 1. Example vertical cross sections of radar reflectivity from the CYC case described in Sect. 5.4. (a) Reflectivity at the Ku band; (b) at the Ka band; (c) at the $\mathrm{W}$ band. The gray area at the bottom of each cross section marks the area below $400 \mathrm{~m}$ altitude, and thus contaminated by surface clutter.

ber 2014 instead. We weighted the observational data so as to remove the effect of the orbit, converting the statistics to uniform sampling over the globe, except for the high latitudes that the orbits of the satellites cannot reach $\left(>65^{\circ}\right.$ for GPM and $>81.8^{\circ}$ for CloudSat). Altogether, approximately $7 \times 10^{6}$ valid GPM Ku-band measurements, $6 \times 10^{6} \mathrm{GPM}$ Ka-band measurements and $1 \times 10^{8}$ CloudSat measurements were used to create the distributions.

The comparison is presented in Fig. 2a. For data points near the sensitivity limits, the radars detect a signal in only a fraction of the points, which makes comparisons to the model complicated. Therefore, we only compare distributions of reflectivities higher than a threshold value, above which the radars detect practically all signals. These thresholds were chosen as $14 \mathrm{dBZ}$ for that GPM Ku-band radar, $18 \mathrm{dBZ}$ for the GPM Ka-band radar, and $-25 \mathrm{dBZ}$ for CloudSat. Fig. 2a shows that overall, NICAM overestimates the amount of detectable cloud, and that the combination of NICAM and the radar model produces higher Ku-band reflectivities for heavy precipitation. On the other hand, the number of lowreflectivity signals seems to be underestimated, which is likely due to NICAM creating too few thin clouds, especially in the liquid phase at low altitudes. This is caused either by the shortcomings of the single-moment microphysics scheme or, in the absence of parameterization, a resolution that is still incapable of adequately modeling non-convective clouds, which would typically be produced by the large-scale 

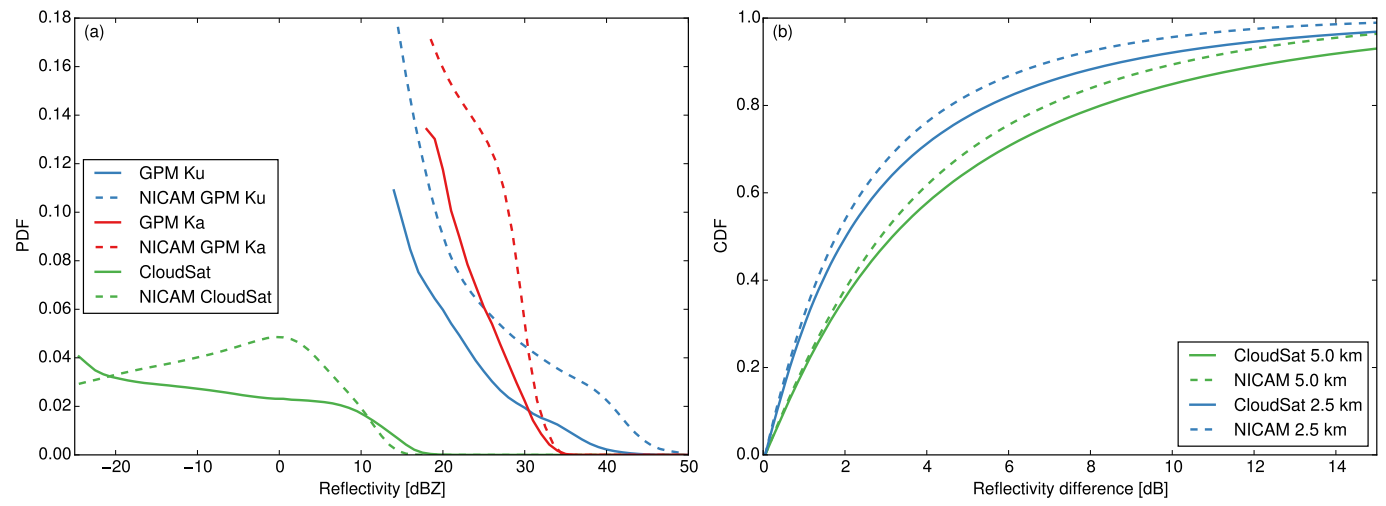

Figure 2. NICAM simulation results for CloudSat and GPM compared to measurements by those satellites. (a) The distributions of radar reflectivity. The curves are normalized such that the area under each curve for the measurements is equal to 1, while the modeled curves are scaled to reflect the difference in the total number of detected signals between the model and the measurements. (b) The cumulative distribution functions (CDFs) of W-band reflectivity difference between points separated horizontally by $5.0 \mathrm{~km}$ (green curves) and $2.5 \mathrm{~km}$ (blue curves), for CloudSat measurements (solid lines) and for our model (dashed lines).

cloud parameterization in coarse-resolution models. Likewise, the most likely explanation for the overestimation of the Ku-band radar signals in heavy precipitation is that the NICAM microphysics model overestimates the number of large drops found in convective rainfall.

Overall, the combination of NICAM and our scattering model produces $83 \%$ more detectable points than GPM at the Ku band, $67 \%$ more than GPM at the Ka band, and $38 \%$ more than CloudSat at the $\mathrm{W}$ band. In spite of these differences, the simulated mean reflectivities are biased by only $+2.6,+1.2$ and $+1.4 \mathrm{~dB}$ relative to GPM Ku band, GPM Ka band and CloudSat, respectively.

As a result of the differences in the reflectivity distribution, the radar computations presented in this study may produce somewhat too optimistic results for the detectability. The results should be interpreted with this in mind. For a more detailed, cloud microphysics-oriented comparison, we direct the reader to Suzuki et al. (2011) and Hashino et al. (2013).

In Fig. 2b, we examine the modeled and measured CloudSat reflectivity difference between horizontally separated points, similar to the study by Kollias et al. (2014). Overall, the correspondence is rather good, indicating that the horizontal variability of reflectivity is captured well by the combination of NICAM and the scattering model. The model overestimates the CDF slightly, predicting that $52 \%$ of reflectivity differences between points separated by $5.0 \mathrm{~km}$ are below $3 \mathrm{~dB}$, while the same percentage for CloudSat measurements is $48 \%$. The corresponding figures at $2.5 \mathrm{~km}$ separation are $67 \%$ for the model and $63 \%$ for CloudSat measurements.

\section{Analysis}

\subsection{Error definition}

In this section, we denote radar reflectivity values as follows: for an idealized radar that does not suffer from nonuniform beam filling, we use $Z_{\mathrm{e}}$ to denote the unattenuated reflectivity at each grid point, $Z_{\mathrm{ss}}$ for the reflectivity with singlescattered attenuation, and $Z_{\mathrm{ms}}$ for the reflectivity with attenuation and multiple scattering. For a real radar whose resolution is degraded due to NUBF effects, we use $\hat{Z}_{\mathrm{e}}, \hat{Z}_{\mathrm{ss}}$ and $\hat{Z}_{\mathrm{ms}}$ as above. All $Z$ values in this section are in logarithmic (dBZ) units.

For each band $(\mathrm{Ku}, \mathrm{Ka}, \mathrm{W})$ and at each grid point, we define the root-mean-square (RMS) error:

$E=$

$\left\{\begin{array}{ll}\sqrt{\frac{1}{2}\left(\left(\hat{Z}_{\mathrm{e}}-Z_{\mathrm{e}}\right)^{2}+\left(\hat{Z}_{\mathrm{ss}}-Z_{\mathrm{ss}}\right)^{2}\right)}, & \text { if } \hat{Z}_{\mathrm{ms}}-\hat{Z}_{\mathrm{ss}}<3 \mathrm{~dB} \\ \infty, & \text { and } Z_{\mathrm{ms}}>Z_{\mathrm{min}} \\ \text { otherwise }\end{array}\right.$,

where $Z_{\min }$ is the minimum detectable signal. For finite values, the error $E$ is a measure of nonuniform beam filling and multiple scattering, and is defined as the RMS average of the unattenuated $\left(\hat{Z}_{\mathrm{e}}-Z_{\mathrm{e}}\right)$ and attenuated $\left(\hat{Z}_{\mathrm{ss}}-Z_{\mathrm{ss}}\right)$ errors. The first term is sensitive only to NUBF, while the latter is also sensitive to attenuation. Infinite values of $E$ indicate that the signal is either attenuated below the detection limit or affected badly by multiple scattering. Each band is labeled as "correct" if

$E<2 \mathrm{~dB}$,

in other words, points where the observed reflectivity is very close to that expected by a radar not affected by NUBF and multiple scattering, and above the detection threshold. In 

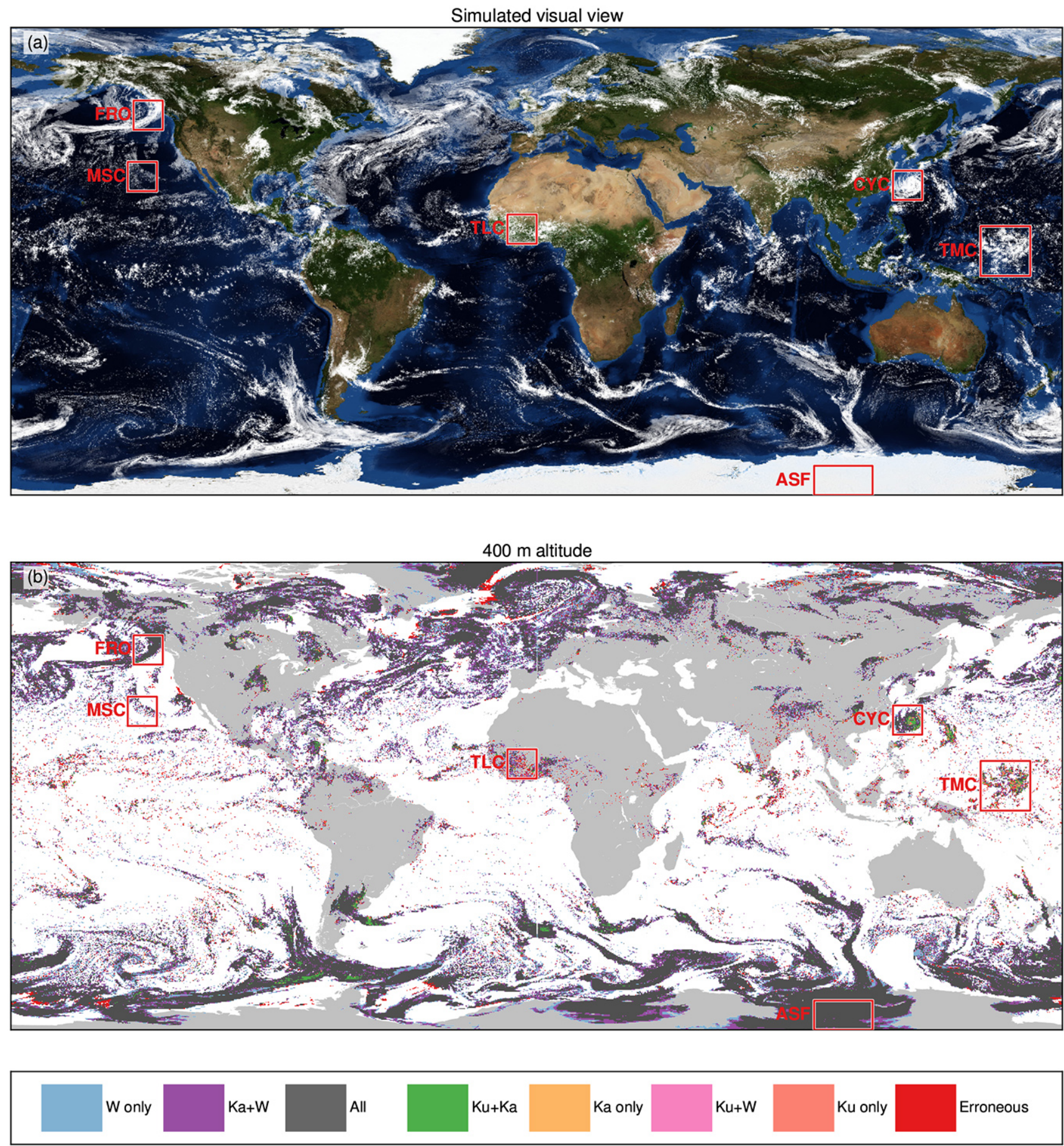

Figure 3. (a) A global overview of the clouds simulated by NICAM. Here, a simulated visual image of the clouds simulated by the model has been overlaid on the "blue marble" image of the Earth (by Reto Stöckli, NASA Earth Observatory). (b) A global map of detectability of the different radar bands at $400 \mathrm{~m}$ above the surface, color coded as shown at the bottom of the figure. In both subfigures, the marked boxes denote the different case studies in Sect. 5: TMC, tropical maritime organized convection (Sect. 5.2); TLC, tropical overland convection (Sect. 5.3); CYC, tropical cyclone (Sect. 5.4); MSC, marine stratocumulus (Sect. 5.5); ASF, Antarctic snowfall (Sect. 5.6); FRO, midlatitude front (Sect. 5.7). 

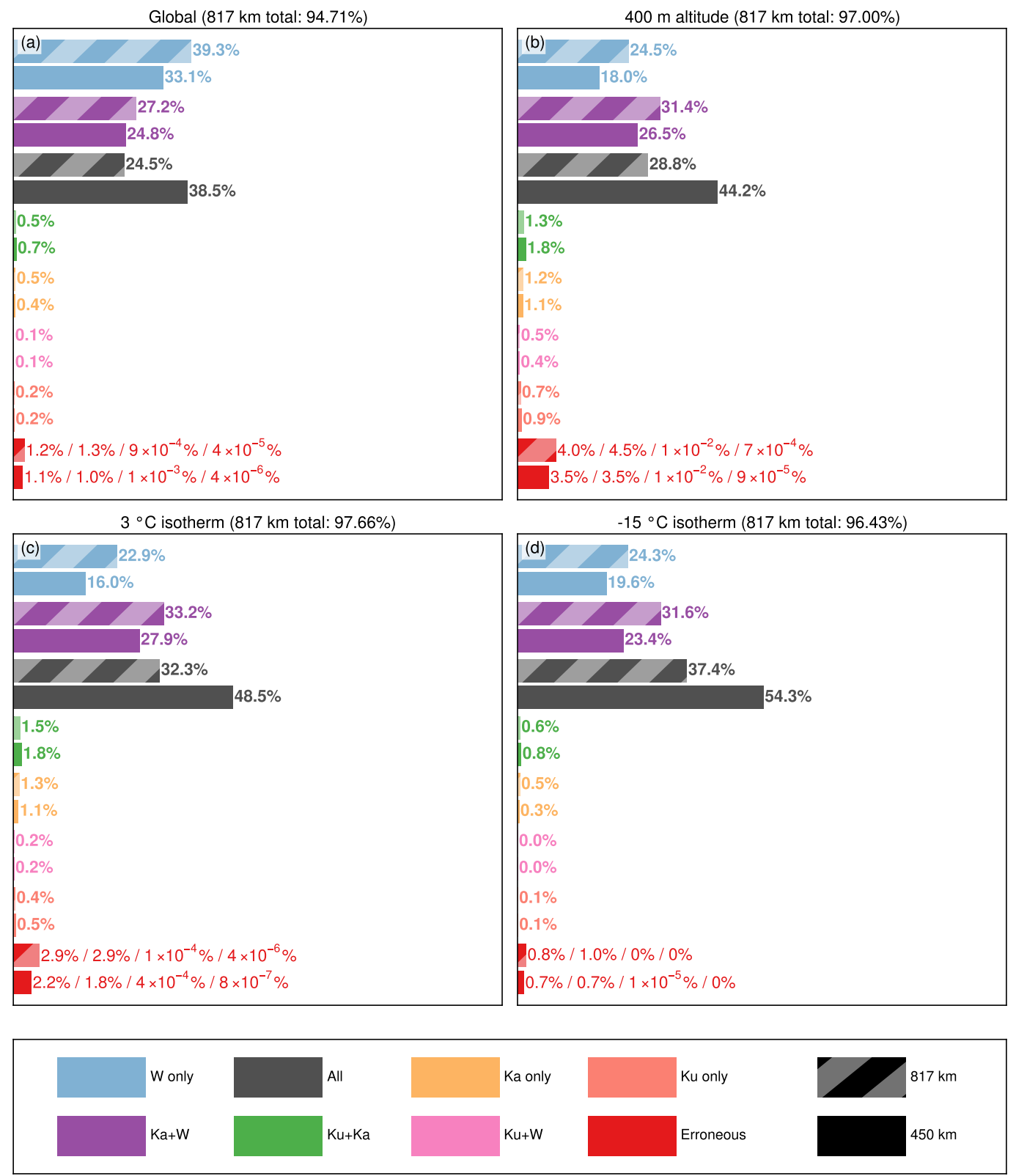

Figure 4. An overview of the detection rates at different radar bands. From top to bottom: blue, only W band detected; purple, Ka and W bands detected; dark gray, all bands detected; green, $\mathrm{Ku}$ and $\mathrm{Ka}$ bands detected; orange, only Ka band detected; pink, Ku and $\mathrm{W}$ bands detected; salmon, only Ku band detected; red, assigned to one of the error categories described in Sect. 4.1. The percentages following the red error category bars correspond to categories 1 (NUBF), 2 (severe NUBF), 3 (multiple scattering) and 4 (attenuation), in that order. The bars for the $450 \mathrm{~km}$ orbit add up to $100 \%$, while those for the $817 \mathrm{~km}$ orbit add up to the percentage given above each subfigure. (a) The global total percentages from the entire model domain; (b) at the level $400 \mathrm{~m}$ from the ocean or land surface; (c) at the $3{ }^{\circ} \mathrm{C}$ isotherm; and (d) at the $-15^{\circ} \mathrm{C}$ isotherm.

these cases, the standard single-scattering-based radar equation can be used "correctly" to retrieve the properties of the particle microphysics. The $2 \mathrm{~dB}$ threshold was chosen as approximately representative of the overall accuracy (accounting for calibration and precision) of the CloudSat and GPM radars (Tanelli et al., 2008; Furukawa et al., 2014).
Where Eq. (27) is not satisfied for any of the three bands, the points are labeled as "erroneous". Most of the points deemed unusable (i.e., failing the above criterion) lack signal to begin with, but some are instead corrupted by attenuation, multiple scattering or NUBF. Some of those may still be recoverable by post-processing, so we define the following er- 

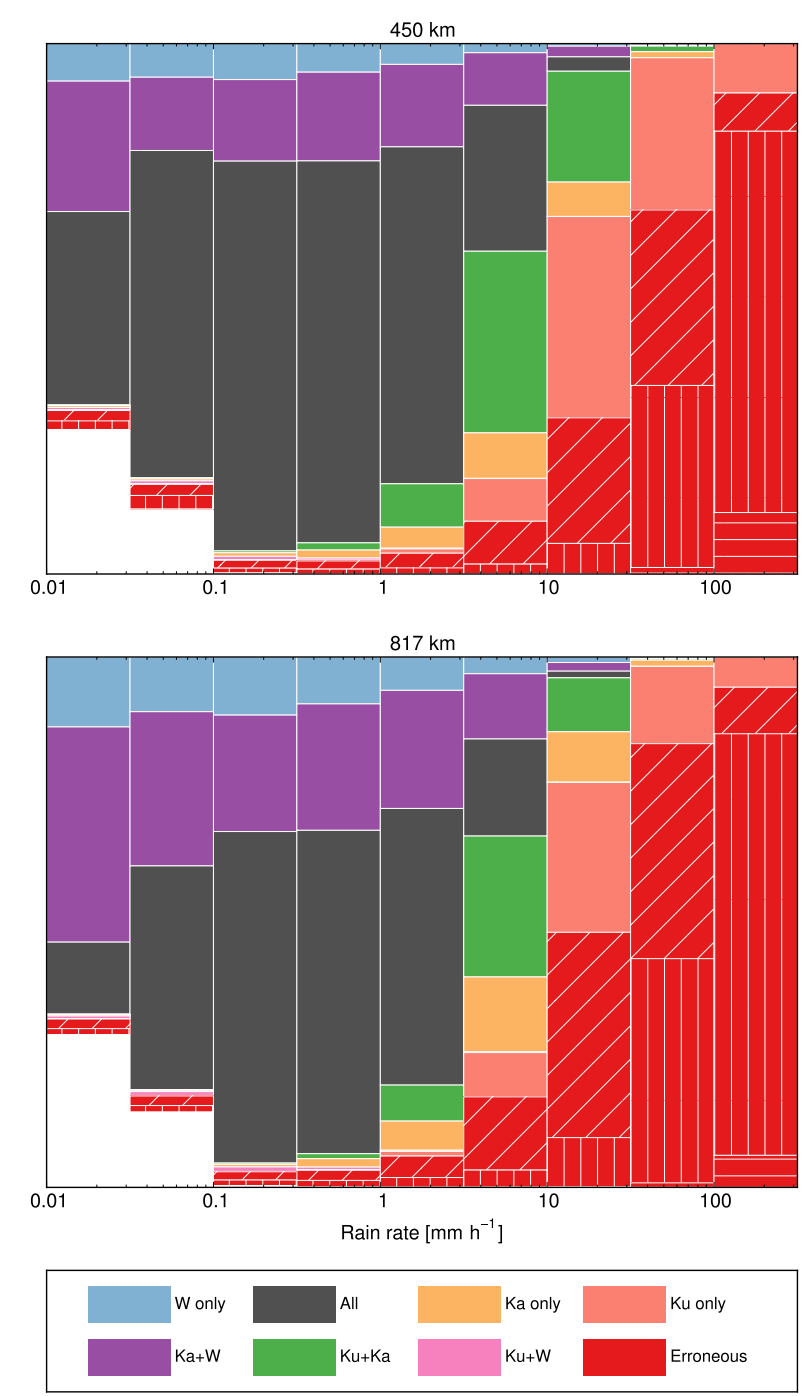

Figure 5. Global statistics of detection segmented by surface precipitation rate. The data used are the reflectivities at $400 \mathrm{~m}$ altitude. The white regions correspond to points that are below the minimum detectable signal at all bands, while the red bars indicate the type of error by their stripe pattern: diagonal stripes for NUBF (error category 1), vertical stripes for severe NUBF (category 2), and horizontal stripes for multiple scattering (category 3 ). Point that are attenuated (category 4) at all bands are rare at all rain rates, and as such, not visible in the figure.

ror categories for cases where $\hat{Z}_{\mathrm{e}}>Z_{\min }$ and $E \geq 2 \mathrm{~dB}$, in order of increasing severity.

1. The signal is corrupted by NUBF, but not irrecoverably: $2 \mathrm{~dB} \leq E<6 \mathrm{~dB}$. Current NUBF-compensating algorithms are expected to mitigate its effects.

2. The signal quality is severely deteriorated by NUBF: $6 \mathrm{~dB} \leq E<\infty$. Algorithms beyond the current state of the art are necessary to compensate at least partially for the NUBF effects in these cases.
3. A signal exists, but is affected by significant multiple scattering: $\hat{Z}_{\mathrm{ms}}-\hat{Z}_{\mathrm{ss}} \geq 3 \mathrm{~dB}$. The effectiveness of existing algorithms that account for MS should be carefully evaluated.

4. A signal would exist, but is attenuated below the detection limit: $\hat{Z}_{\mathrm{ms}}<Z_{\mathrm{min}}$.

\subsection{Signal availability}

Each point in the modeled volume is assigned into categories that are defined according to which radar bands are available and trustworthy at the given point. Such classification allows us to assess both the availability of multi-frequency techniques and the capability of the radar to cover the entire measurement volume.

The different error modes are also assigned their own categories: at each point, if all three bands are unavailable either due to being below the detection limit or being assigned to one of the error categories described in Sect. 4.1, we select the least severe error mode available to the three bands. For example, if at a given point, the Ku-band signal is below the detection limit, the Ka band has a signal but is affected by severe NUBF (error category 2), and the W band is attenuated below the minimum detectable signal (category 4 ), we assign that point to category 2 .

\section{Results}

Using the approach outlined in Sect. 4, we analyzed the radar signal availability in the entire model domain. The results are presented here in terms of maps and global statistics. We also more closely analyzed six regions of the globe that represent different meteorological conditions that give rise to important targets or particularly challenging conditions for radar measurements.

\subsection{Global}

In Fig. 3 we present a global overview of the results. Figure 3a shows a simulated view of the clouds produced by the model. This image was created by generating a white cloud mask, whose thickness was given by the liquid water path "LWP" as $1-\exp (-c \cdot \mathrm{LWP})$, where the coefficient $c$ was determined experimentally by visual comparison to satellite images of clouds. The mask was then overlaid on the NASA "blue marble" image of the Earth.

Figure $3 b$ gives an overview of the detection of surface precipitation over the entire globe from the $450 \mathrm{~km}$ orbit with the different radar bands. Here, the level $400 \mathrm{~m}$ above the surface is shown as this is the lowest level that we expect to be able to observe without the radar signal being corrupted by the surface echo.

An inspection of Fig. $3 b$ shows that most radar bins with a signal are colored either dark gray (all three radar bands 

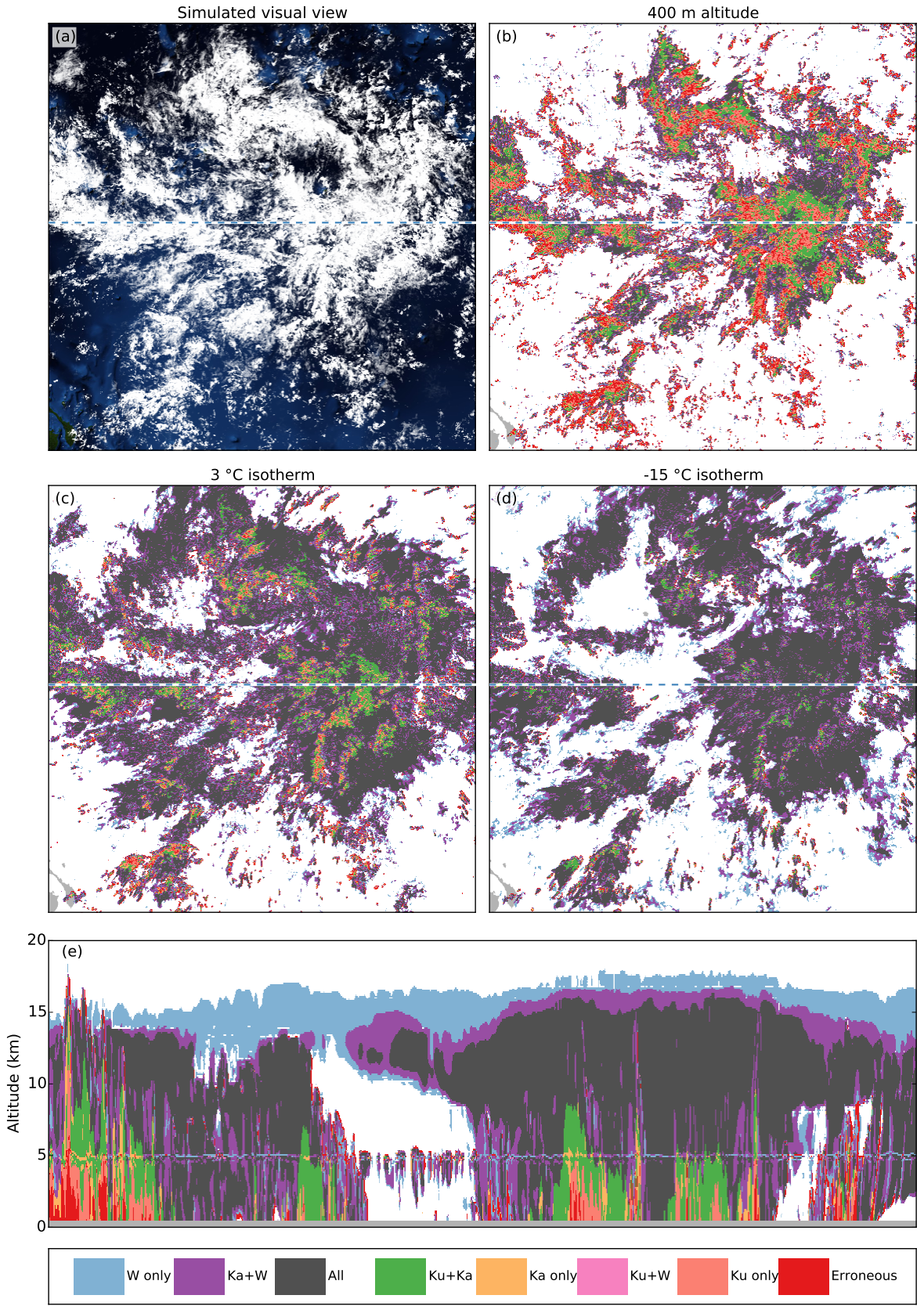

Figure 6. An overview of the radar band availability in the case study of tropical maritime organized convection (Sect. 5.2; TMC in Fig. 3). (a) A simulated visual view, generated as with Fig. 3a. (b) The radar band availability at the $400 \mathrm{~m}$ level. (c) As in (b), but at the $3{ }^{\circ} \mathrm{C}$ isotherm. (d) As in (b), but at the $-15^{\circ} \mathrm{C}$ isotherm. (e) A vertical cross section of the region along the blue-white dashed line shown in (a-d).

available) or purple (Ka and $\mathrm{W}$ bands available). The latter categorization occurs when the Ku-band reflectivity falls below the radar sensitivity or because it is heavily affected by NUBF. Blue points, denoting detection only at the $\mathrm{W}$ band, are present in some regions, being most common in the high latitudes and subtropics; this indicates that they arise from snowfall or scattered shallow convection. Green color (which shows bins where the $\mathrm{W}$ band has been attenuated) leaving only the $\mathrm{Ku}$ and $\mathrm{Ka}$ bands available, is fairly rare, and occurs mainly in the middle of frontal and convective systems. The other availability classes are found in very few places.

Points that suffer from one of the error modes described in Sect. 4.1, denoted by red color, have two main sources. The first source is the scattered areas of erroneous points at the edges of convective cells, occurring most commonly at and around the intertropical convergence zone. There, the sharp 

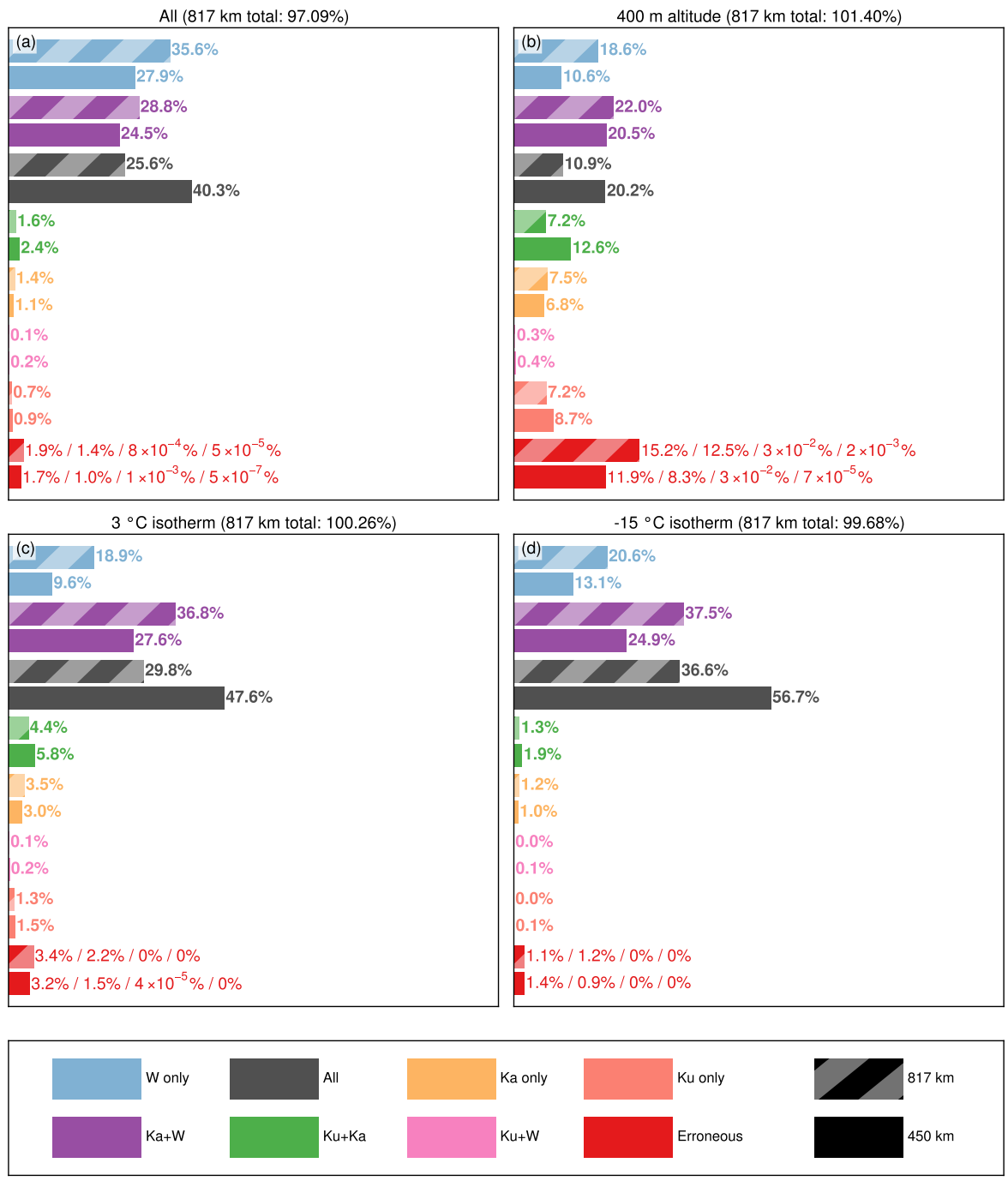

Figure 7. As in Fig. 4, but limited to the region of Fig. 6 (Sect. 5.2; TMC in Fig. 3).

gradients of reflectivity give rise to NUBF, and the heavy precipitation in these systems often causes attenuation and multiple scattering effects. The other source of errors occurs when a cloud base or top is located in the bin vertically adjacent to the $400 \mathrm{~m}$ level. When this occurs, the nonzero radar pulse length causes signal to bleed to the neighboring range bins. Hence, the difference between the ideal and measured radar reflectivity is large, and the bin is marked as suffering from NUBF. This results in the relatively uniform areas of the map marked as erroneous, which are found mainly at the high latitudes.

The inspection of Fig. 4, which shows a bar plot of the fractions of different detection categories, confirms the qualitative assessment above. The general trend is that at higher altitudes (or lower temperatures) the number of erroneous points tends to decrease. A comparison of Fig. 4a and d suggests that of the points where only the $\mathrm{W}$ band is able to make a detection, most are high-altitude ice clouds at temperatures lower than $-15^{\circ} \mathrm{C}$. The most notable difference between the 450 and $817 \mathrm{~km}$ orbits is the decreased availability of triple-frequency measurements at $817 \mathrm{~km}$ : the $450 \mathrm{~km}$ orbit has roughly 1.6 times as many bins with all three bands available in total, and 1.9 times as many at the nearsurface $400 \mathrm{~m}$ level; in the $450 \mathrm{~km}$ orbital scenario, these grid points usually fall into the " $\mathrm{Ka}+\mathrm{W}$ " category. The number of points marked as erroneous is also larger for the higher orbit. The error rate also increases significantly at $817 \mathrm{~km}$. Figure 5 demonstrates how the categories characterized by low reflectivities are apparent at low precipitation rates, while attenuation-related and erroneous categories are most common in heavy precipitation. The reasons underlying these trends are illustrated by the case studies in the following subsections. 
Simulated visual view

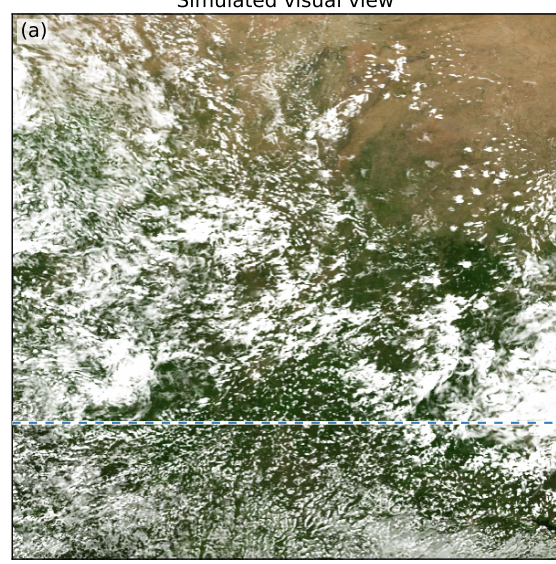

$3{ }^{\circ} \mathrm{C}$ isotherm
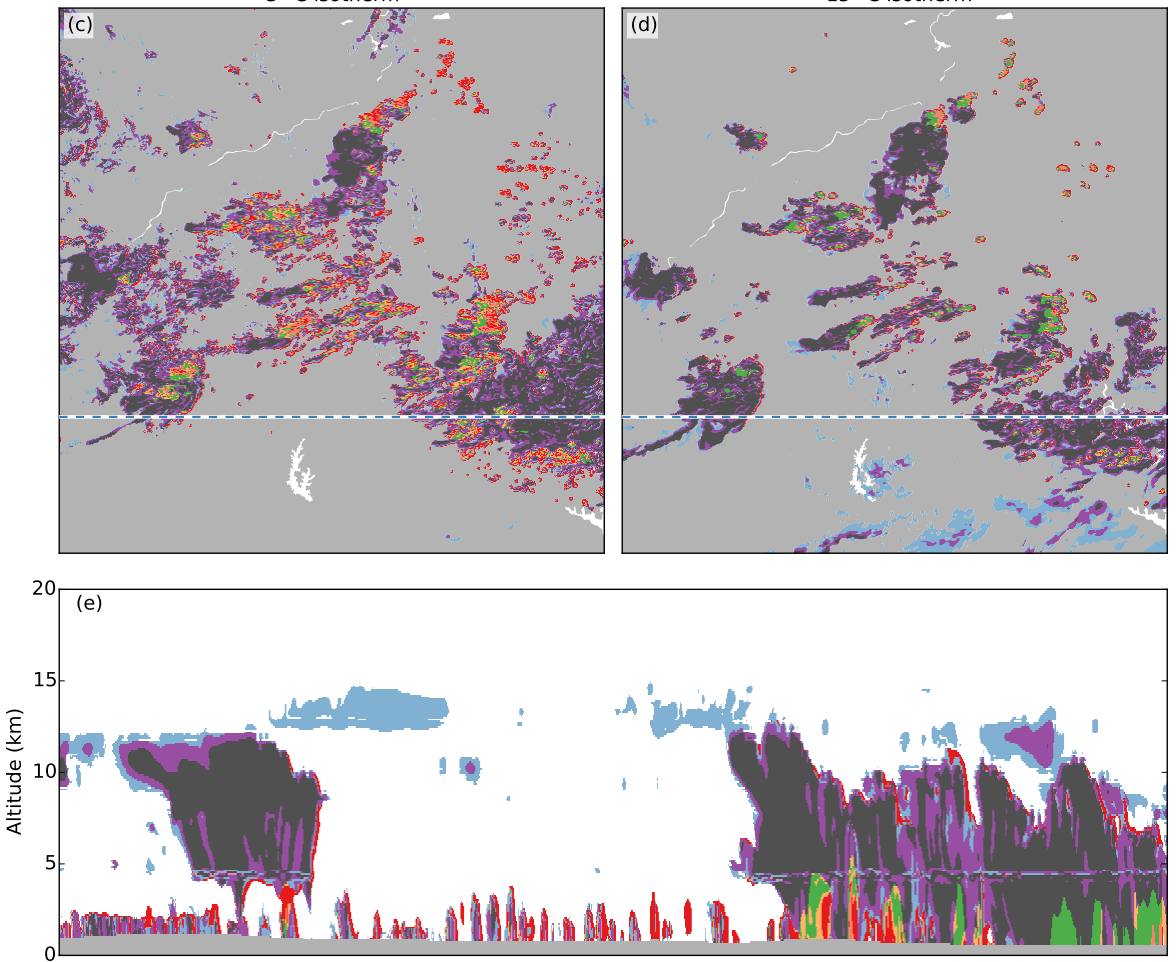

$400 \mathrm{~m}$ altitude

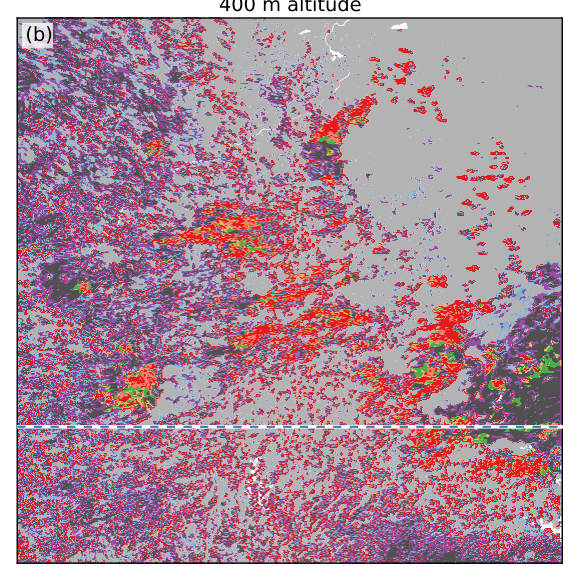

$-15^{\circ} \mathrm{C}$ isotherm

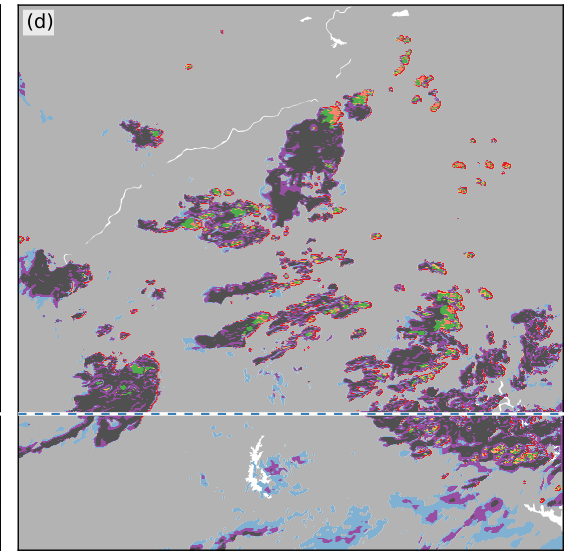

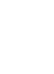



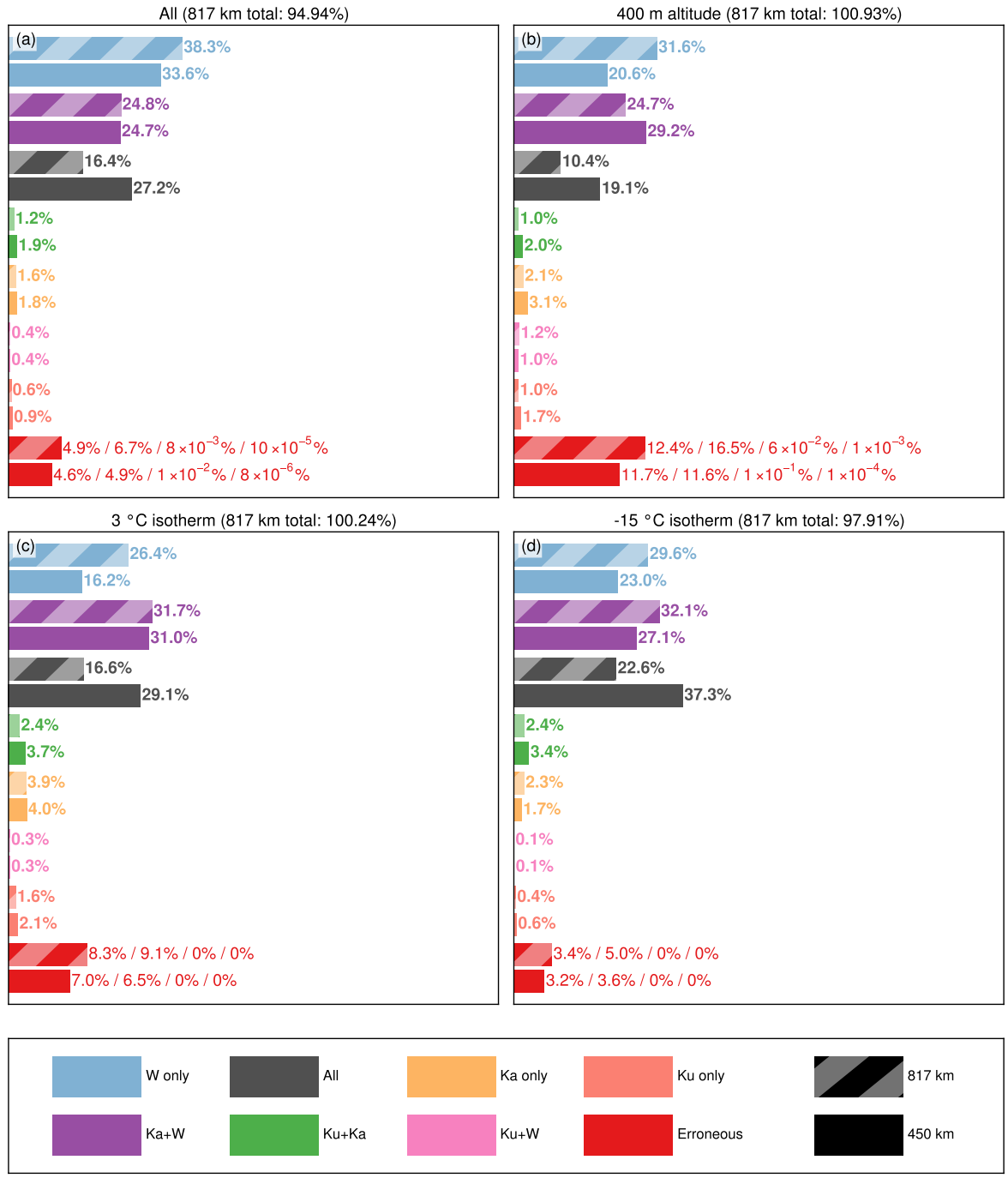

Figure 9. As in Fig. 4, but limited to the region of Fig. 8 (Sect. 5.3; TLC in Fig. 3).

From a radar perspective, this region is characterized by both heavy attenuation and significant NUBF. As shown in Fig. 6, the W-band signal is sufficiently attenuated in many places as to be undetectable in the bottom $4-5 \mathrm{~km}$ of the vertical profile.

The signal is also marked as erroneous in many of the points of the lower atmosphere. Figure 7 a shows that in the entire three-dimensional region, $3.6 \%$ of the points are assigned to one of the error categories for the $817 \mathrm{~km}$ orbital scenario, while for the $450 \mathrm{~km}$ orbit, this decreases to $3.0 \%$. For the surface precipitation measurements at $400 \mathrm{~m}$ altitude (Fig. 7b), the errors are much more common, with 29 and $19 \%$ flagged as erroneous for the 817 and $450 \mathrm{~km}$ orbits, respectively. Typically, the error is a combination of attenuation and multiple scattering at the $\mathrm{W}$ band, NUBF at the $\mathrm{Ku}$ band, and one or more of these at the Ka band. As we select the least severe error according to the criteria of Sect. 4.1, most points are then flagged as either NUBF (error category 1) or severe NUBF (category 2). The frequent occurrence of the specific combination of Ku-band NUBF and Wband attenuation can be seen in the large fraction of measurements where the Ka band is the only channel that yields an acceptable signal, around $7 \%$, which is far higher than in the global total occurrence of this category.

The errors decrease rapidly with increasing altitude: at the $3{ }^{\circ} \mathrm{C}$ isotherm (Figs. $6 \mathrm{c}$ and $7 \mathrm{c}$ ), still below the melting layer, the total error rates have decreased to $5.4 / 4.7 \%$, and at $-15^{\circ} \mathrm{C}$ (Figs. $6 \mathrm{~d}$ and $7 \mathrm{~d}$ ), they are lower still, with $2.3 \%$ for both orbits. An inspection of the vertical cross section in Fig. 6e suggests that the decrease of the error rate is caused by both decreasing attenuation and increasing homogeneity (and hence weaker NUBF) with increasing altitude. Interestingly, NUBF is so ubiquitous in this case that in spite of the lower sensitivity in the $817 \mathrm{~km}$ orbit scenario, at the $400 \mathrm{~m}$ 

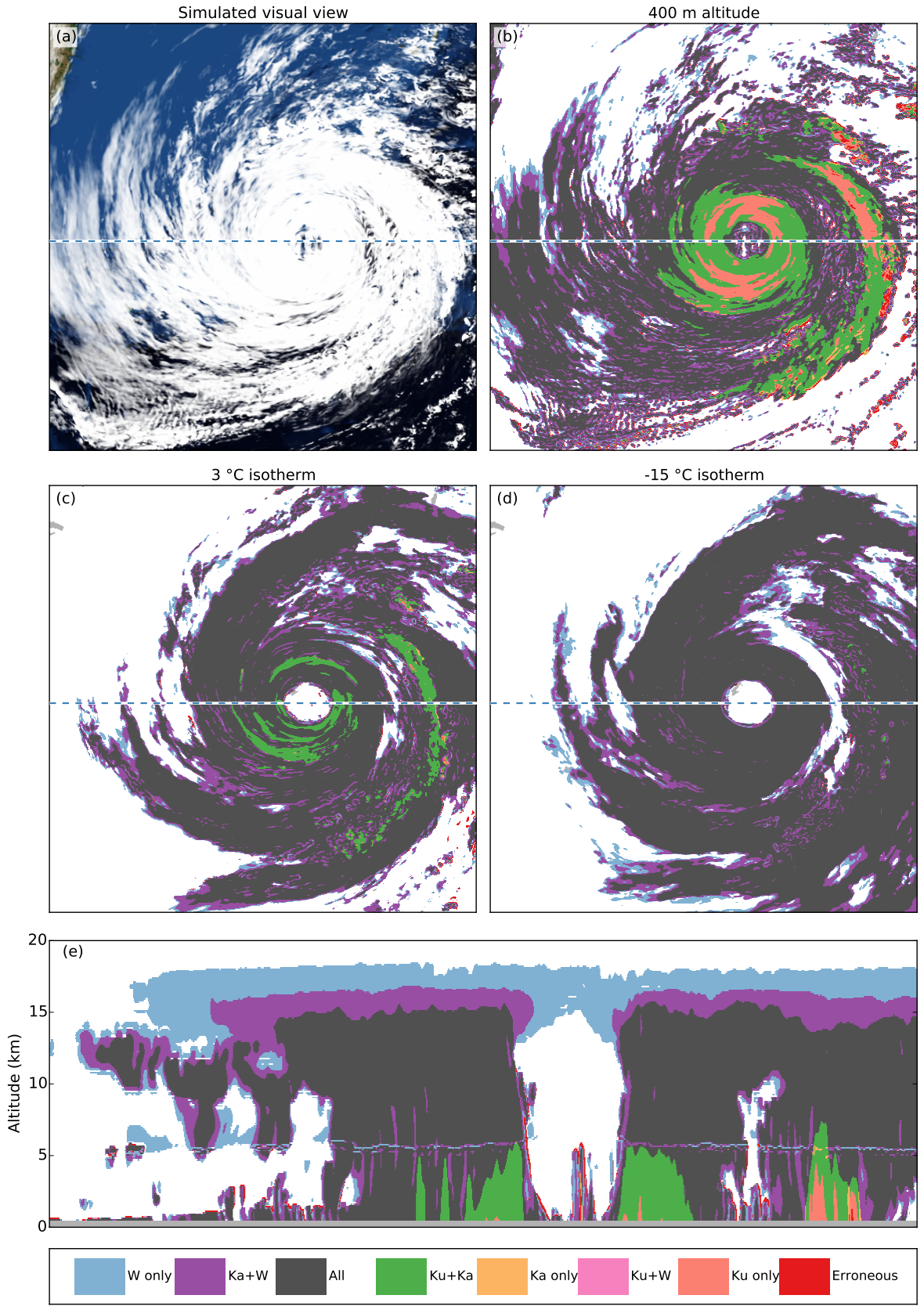

Figure 10. As in Fig. 6, but for the tropical cyclone (Sect. 5.4; CYC in Fig. 3).

and $3{ }^{\circ} \mathrm{C}$ surfaces the spatial spreading of the signal due to NUBF results in a larger number total points with detected signals at the $817 \mathrm{~km}$ orbit than at the $450 \mathrm{~km}$ orbit. The additional signals arise from glancing hits and are therefore of dubious value; the number of trustworthy points actually decreases in the higher orbital scenario.

\subsection{Tropical overland convection}

This case is similar to the first case, but instead exhibits more scattered convection with smaller cells. The region is located over a land surface in the intertropical convergence zone over western Africa, covering most of Burkina Faso, Ghana, Ivory Coast, Liberia and southern Mali. Figure 8 shows that the cloud activity in the region consists of shallow, fine-grained convection in the $0-3 \mathrm{~km}$ layer, overlaid by a few largerscale, more homogeneous systems.

From the NUBF perspective, the surface precipitation in this case represents the worst-case scenario in the entire data set. The error rates for the $817 / 450 \mathrm{~km}$ orbits are $13 / 11 \%$ for the full three-dimensional region and $29 / 23 \%$ for the $400 \mathrm{~m}$ 

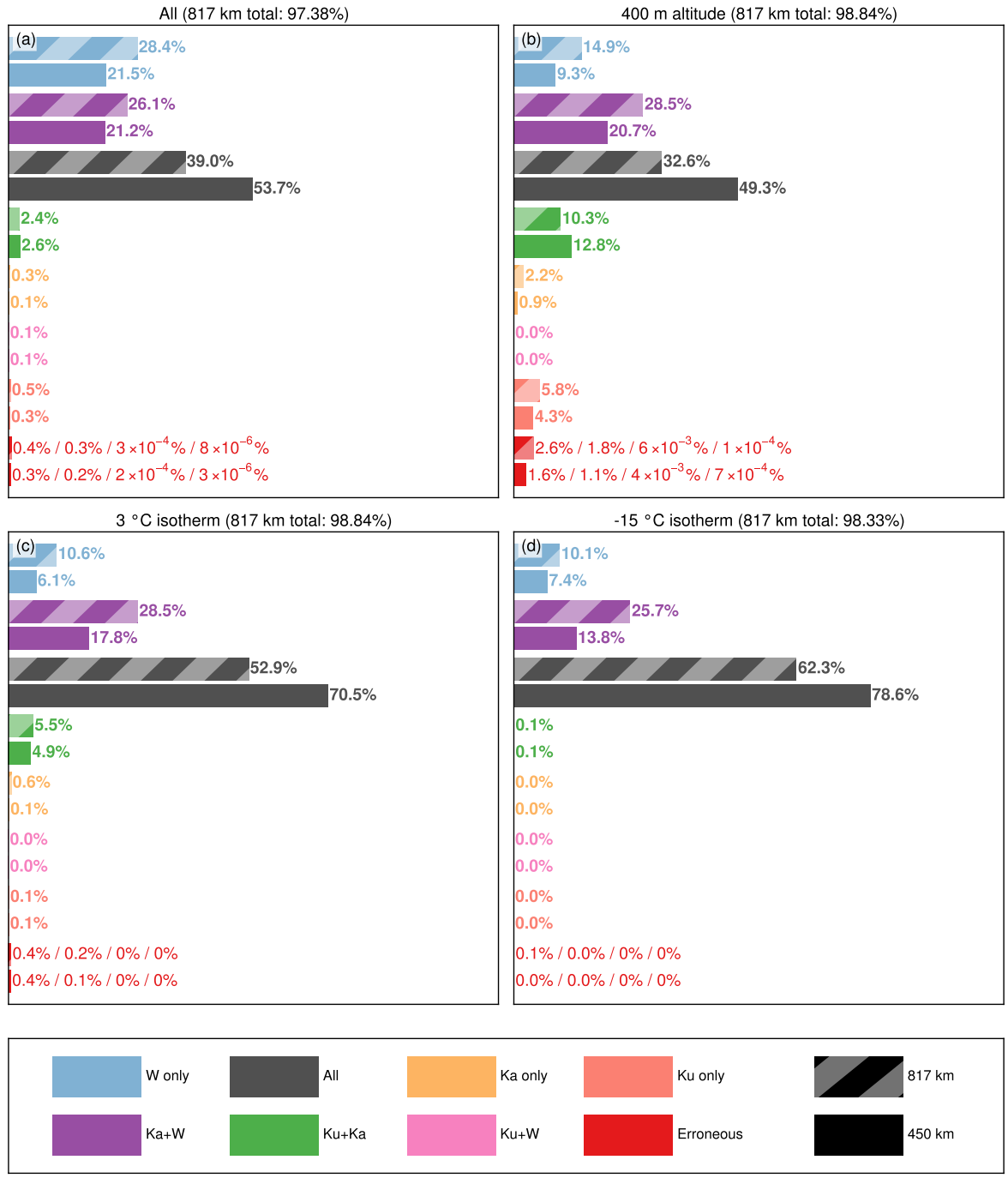

Figure 11. As in Fig. 4, but limited to the region of Fig. 10 (Sect. 5.4; CYC in Fig. 3).

surface (Fig. 9). Again, these rates decrease at higher altitudes, but not as strongly as with the oceanic case above. Conversely, attenuation-related errors are much rarer in this case, with only $1-3 \%$ of points in the "Ku only", "Ku $+\mathrm{Ka}$ " and "Ka only" categories.

\subsection{Tropical cyclone}

For the third case study, we inspected a region where NICAM modeled a tropical cyclone in the East China Sea and western Pacific Ocean, with an eye close to the island of Okinawa. As in the TMC case of Sect. 5.2, the clouds and precipitation reach high altitudes, around $18 \mathrm{~km}$, but their structure is much more homogeneous (Fig. 10). Accordingly, NUBF causes far fewer errors in this case, and the total error rate is correspondingly lower, $0.73 / 0.55 \%$ for the entire domain and $4.4 / 2.7 \%$ for the $400 \mathrm{~m}$ level (Fig. 11). In this case, the low error rate stems largely from the ability of the Ku-band radar to penetrate almost the entire system; this can be seen from the relatively large number of points, around $5 \%$ at $400 \mathrm{~m}$, where only the $\mathrm{Ku}$ band gives a signal; the W-band signal is attenuated below the detection limit in over $10 \%$ of the points at that level.

\subsection{Marine stratocumulus}

The fourth region contains low-level drizzling marine stratocumulus clouds located in the eastern Pacific Ocean between California and Hawaii. Here, NICAM simulates lowlying clouds with tops around $1 \mathrm{~km}$ altitude, lower than is typical for these clouds (Leon et al., 2008).

In this case, Fig. 12 indicates that the predominant error mode is NUBF in the vertical direction; that is, blurring caused by the pulse length rather than the width of the antenna pattern. This, together with the horizontal inhomogeneity, causes relatively high error rates (Fig. 13), though not as 

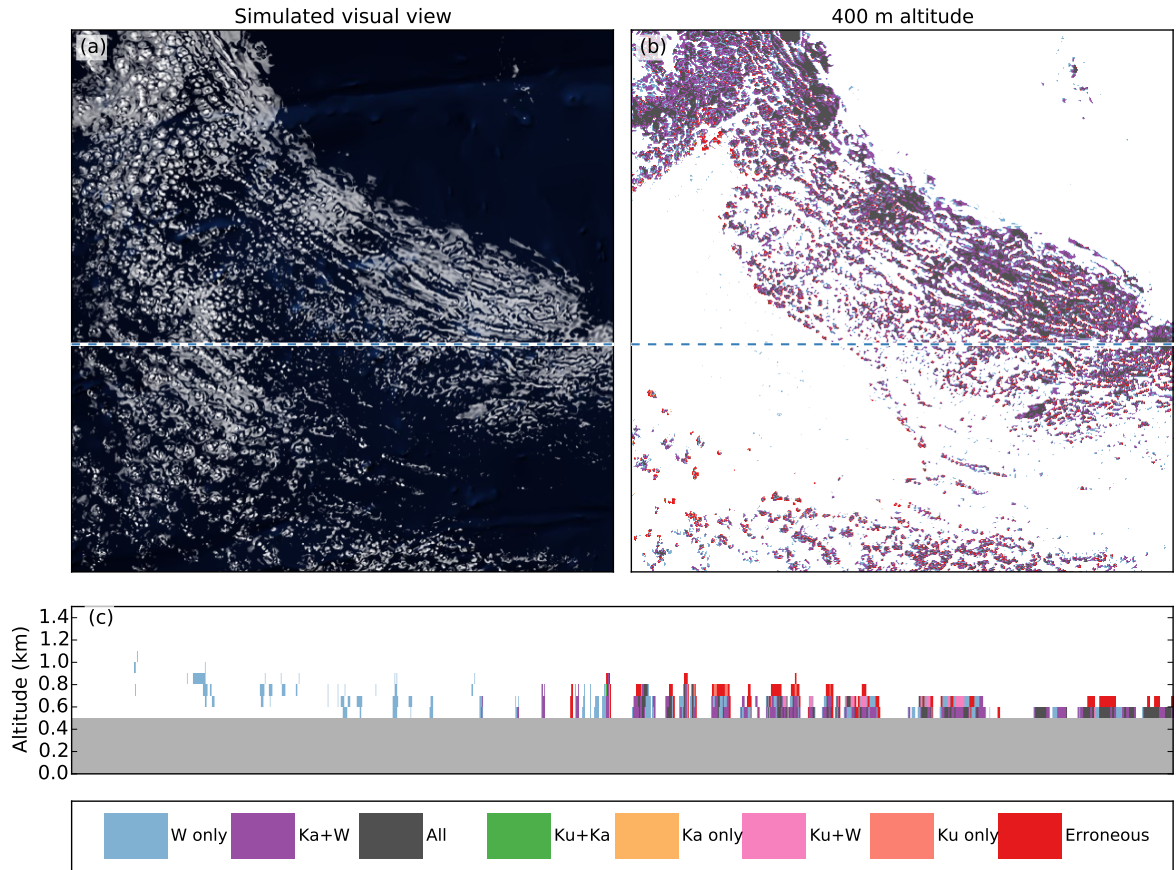

Figure 12. As in Fig. 6, but for the maritime stratocumulus (Sect. 5.5; MSC in Fig. 3), and with the levels restricted to the $400 \mathrm{~m}$ altitude.

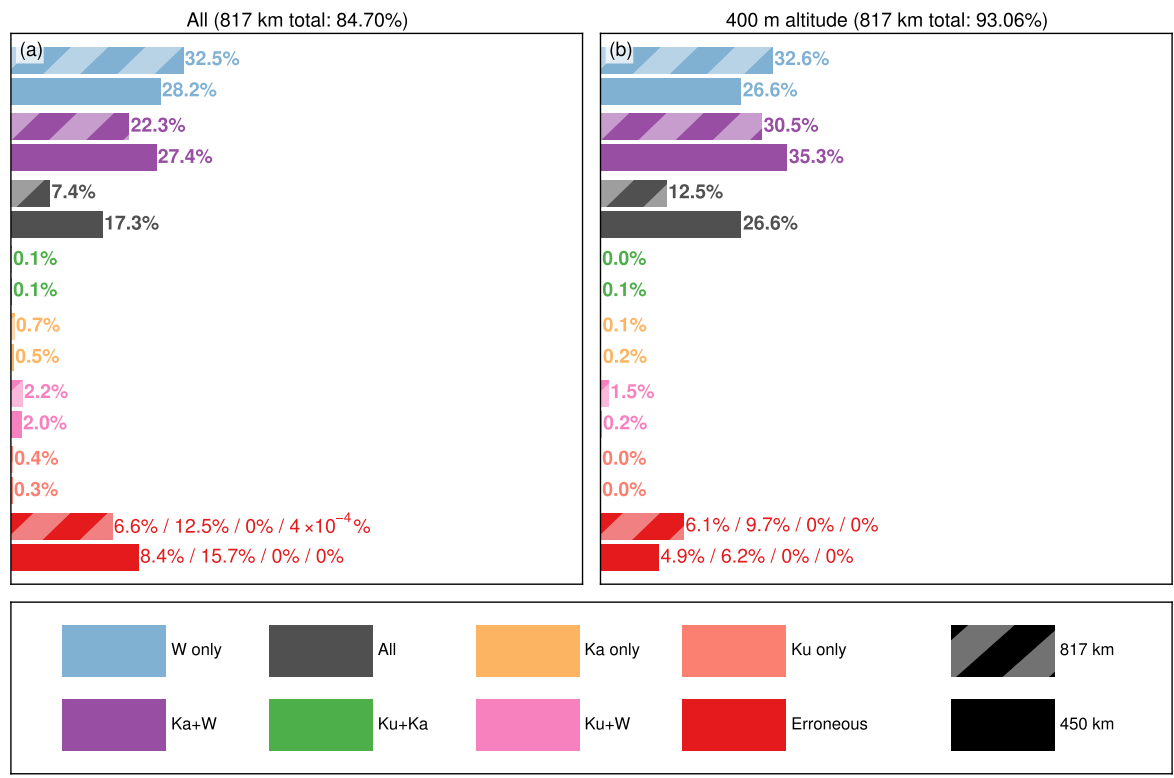

Figure 13. As in Fig. 4, but limited to the region of Fig. 12 (Sect. 5.5; MSC in Fig. 3), and only showing the $400 \mathrm{~m}$ level.

drastic as those in the convective cases. This scene also has many clouds, relatively speaking, with weak radar reflectivity. This is most apparent in how the simultaneous availability of all three bands changes from the $450 \mathrm{~km}$ orbit to the $817 \mathrm{~km}$ orbit in Fig. 13a. However, it should be noted that in this case, the positive reflectivity bias of the model may cause the availability of the Ku band in particular to be overestimated.

\subsection{Antarctic snowfall}

In the fifth case, the precipitation consists of stratiform snowfall in continental Antarctica. As it was winter in Antarctica at the time of the simulation, and the ice surface is at high 

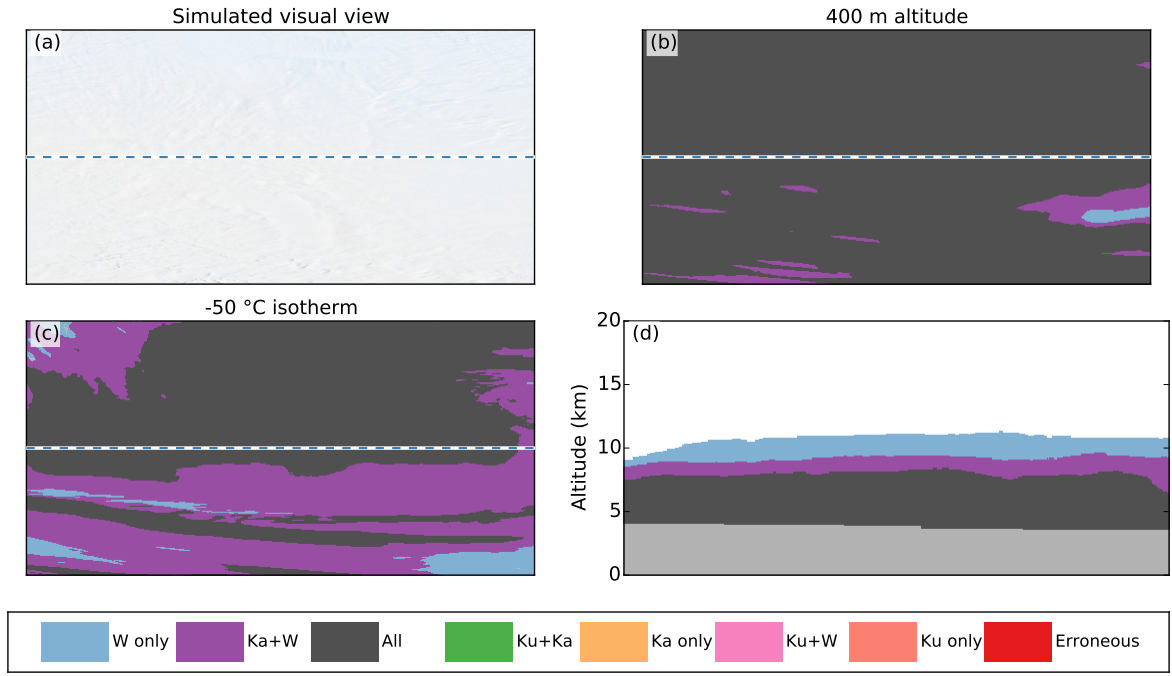

Figure 14. As in Fig. 6, but for the Antarctic snowfall (Sect. 5.6; ASF in Fig. 3), showing the $-50^{\circ} \mathrm{C}$ isotherm instead of 3 and $-15^{\circ} \mathrm{C}$, and giving the vertical cross section in $(\mathrm{d})$.
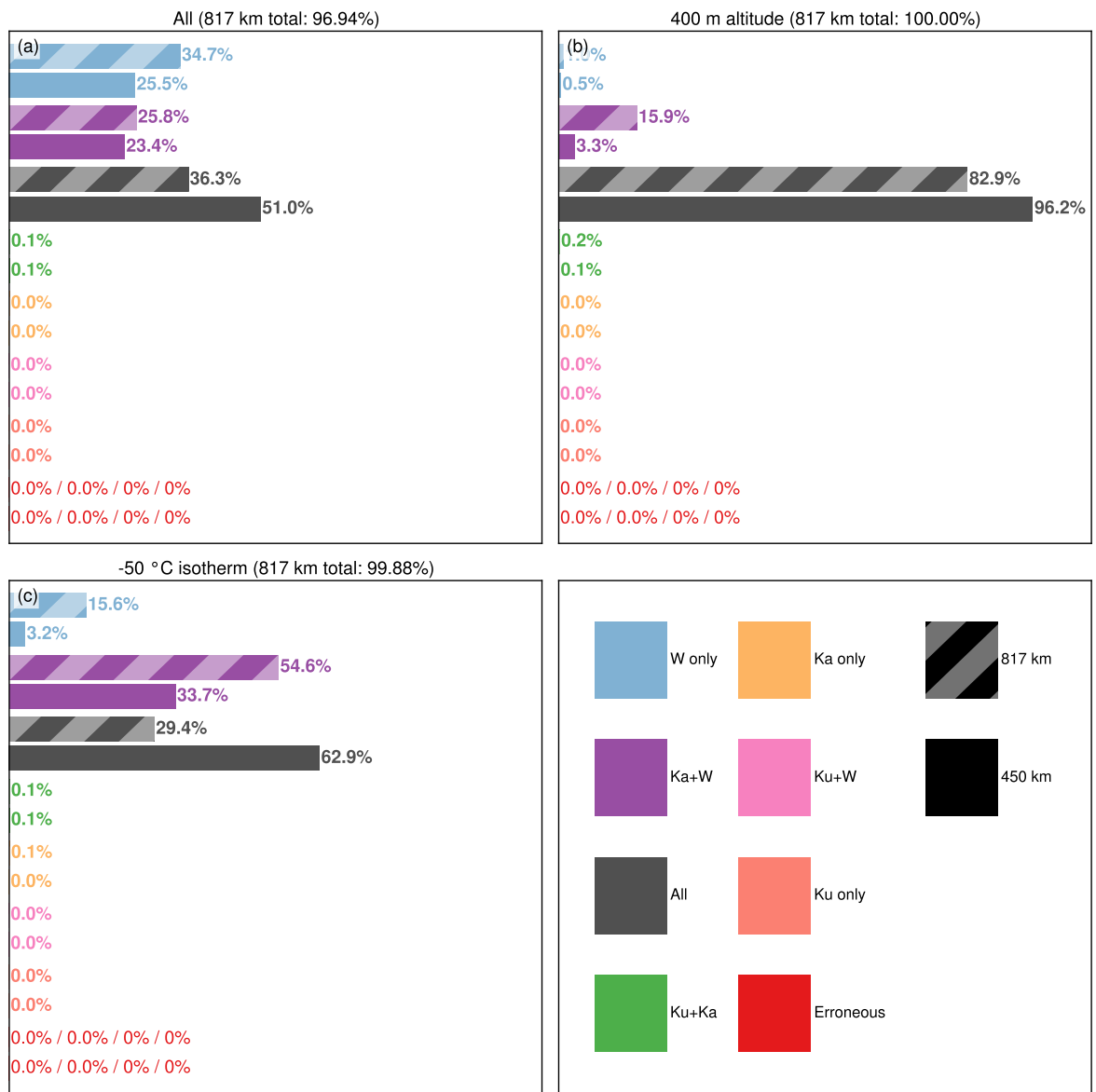

Figure 15. As in Fig. 4, but limited to the region of Fig. 14 (Sect. 5.6; ASF in Fig. 3), and showing the $-50^{\circ} \mathrm{C}$ isotherm instead of 3 and $-15^{\circ} \mathrm{C}$. 

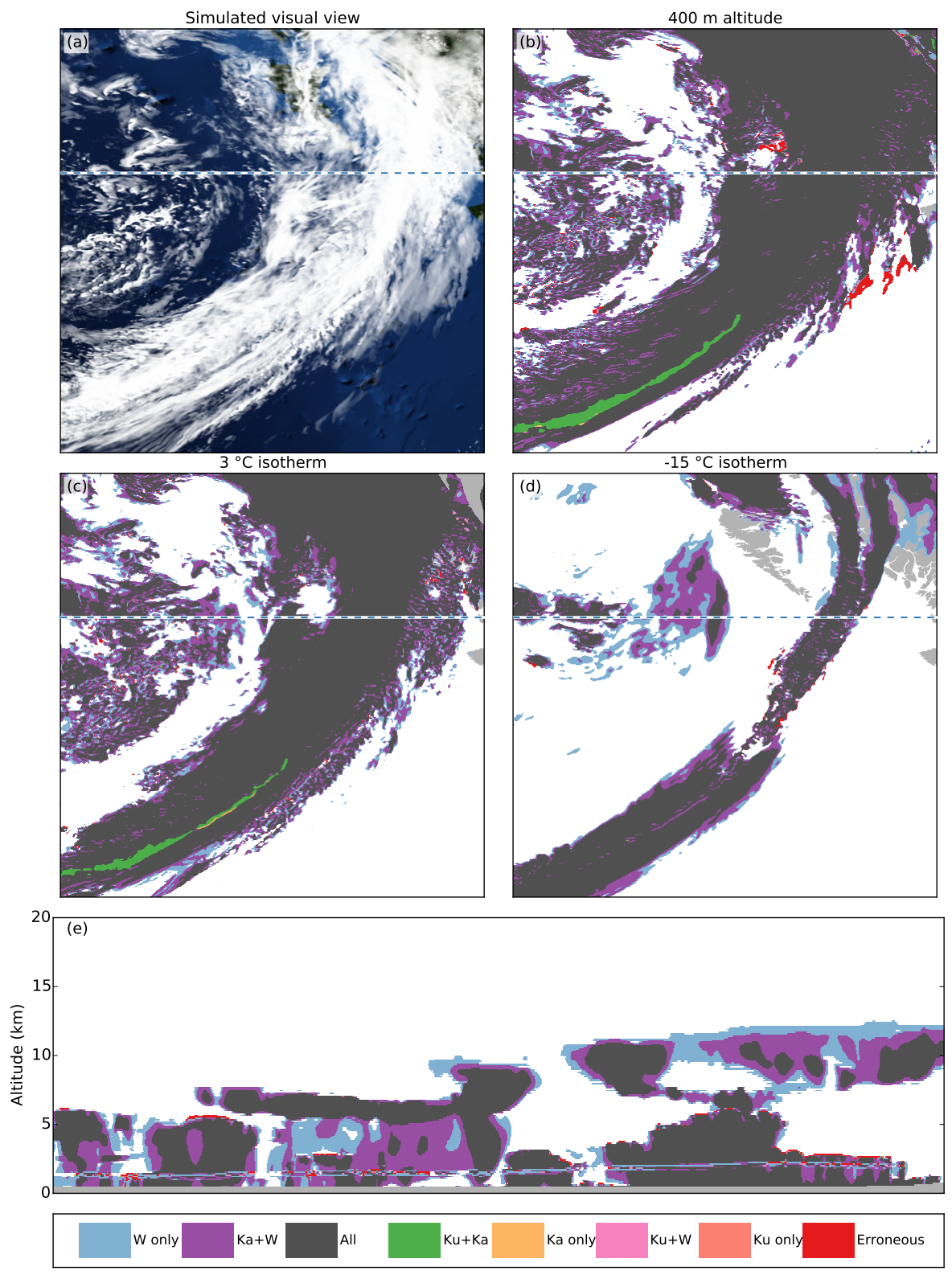

Figure 16. As in Fig. 6, but for the midlatitude front (Sect. 5.7; FRO in Fig. 3).

altitude, over $3 \mathrm{~km}$ a.s.l. in the majority of the region, the surface temperature is well below $-15^{\circ} \mathrm{C}$. Thus, in Fig. 14 we inspect the $-50^{\circ} \mathrm{C}$ isotherm instead of the 3 and $-15^{\circ} \mathrm{C}$ in the other cases. That isotherm is located roughly $0.5-1.5 \mathrm{~km}$ below the cloud top.

In this case, we see in Fig. 15 the largest differences between the performance of the two orbital scenarios at the $-50^{\circ} \mathrm{C}$ level. Attenuation is negligible as the precipitation consists of dry snow, as is the NUBF because the system is highly uniform in structure. Thus, in high-latitude snowfall cases the limiting factor for the performance of the radar appears to be the sensitivity, and even the relatively modest $5 \mathrm{~dB}$ sensitivity difference between the two orbits has a significant effect on the detectability and the availability of multi-frequency retrievals at this level.

\subsection{Midlatitude front}

The final case examined is a maritime frontal scenario located off the west coast of Canada. The prominent cloud features include a cold front with banded convection, extensive stratiform precipitation, and shallow precipitating postfrontal convection (Fig.16).

The majority of this scene is dominated by the "three frequencies usable" category that is associated with the widespread stratiform precipitation (Fig. 17). There is a band 

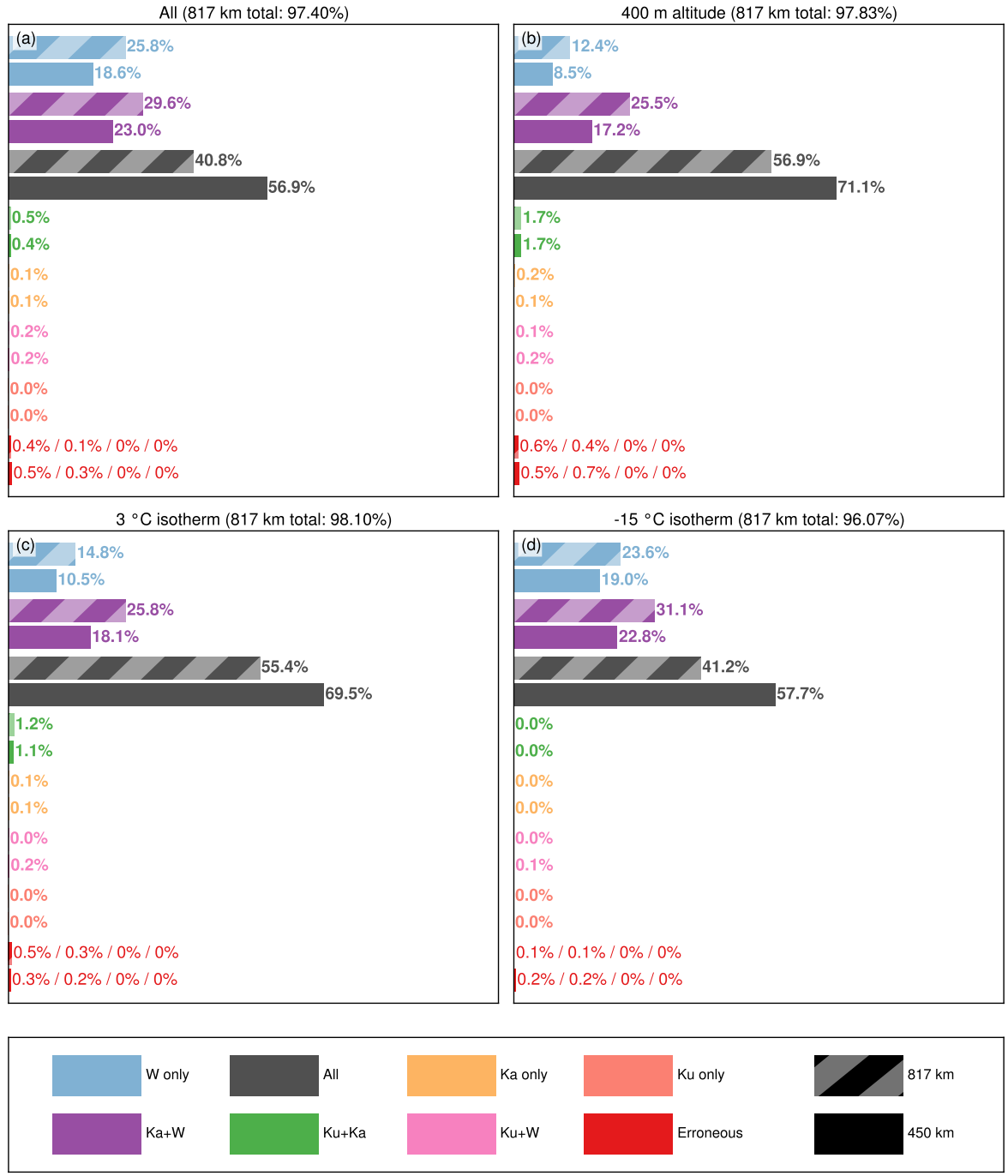

Figure 17. As in Fig. 4, but limited to the region of Fig. 16 (Sect. 5.7; FRO in Fig. 3).

of precipitation along the cold front where that falls into the "Ku $+\mathrm{Ka}$ " category from the freezing level to the surface. The "Ku only" category rarely occurs in this scenario regardless of the orbital scenario. At the near-surface level, a moderate number of pixels fall into the "erroneous" category due to edge effects that, in practice, are easily identified and handled. The post-frontal convection demonstrates the features common to shallow cumulus, including the reflectivity at $\mathrm{Ka}$ and $\mathrm{Ku}$ bands falling below the minimum detectable signal, and frequent edge-effects on both the $\mathrm{Ku}$ and Ka bands, which increase by approximately $50 \%$ at the $817 \mathrm{~km}$ orbit relative to the $450 \mathrm{~km}$ orbit.

\section{Conclusions}

In this paper, we have evaluated the performance of a proposed spaceborne $\mathrm{Ku}-/ \mathrm{Ka}-/ \mathrm{W}$-band triple-frequency radar configuration using a radar simulation from global atmospheric model data. The performance was quantified in terms of the detectability and quality of a signal at one or more of the three frequency bands.

Overall, our results indicate that the proposed combination of radar frequencies can detect almost any cloud or precipitation above the minimum detectable signal of the $\mathrm{W}$ band channel. This is mainly due to the ability of the $\mathrm{Ku}$ band, and to a lesser extent the Ka band, radars to penetrate through the vertical structure of precipitation. According to the simulations we performed, the Ku-band radar can detect precipitation at the surface even in the heavy precipitation cases without having its signal attenuated below the detection limit or corrupted by multiple scattering. However, the contribution from multiple scattering may be underestimated in heavy rain because such precipitation is often accompanied by hail, which is not modeled in NICAM, and which is 
a major contributor to multiple scattering in spaceborne radar signals (Battaglia et al., 2010).

While heavy attenuation blocks the W-band channel in heavy precipitation, it is still available and reliable in roughly $85 \%$ of all radar bins with a signal. In the majority of those bins where the $\mathrm{W}$ band is not available, the other two bands also contain errors from either attenuation, multiple scattering or nonuniform beam filling. This is primarily because all of these error modes coexist in heavy convective rainfall. When interpreting the conclusions concerning the detection of regions with low radar reflectivity, it should be remembered that the detection rate estimates presented here are likely to be somewhat overestimated because of the tendency of the combination of NICAM and our scattering model to produce higher reflectivities than are actually measured. It is also known that CloudSat, with a W-band sensitivity only slightly worse than our proposed configuration, misses over $35 \%$ of all clouds (Marchand et al., 2008; Mace et al., 2009), indicating that our radar would also commonly fail to detect thin clouds.

Multi-frequency techniques obviously require more than one band to be available simultaneously. Triple- or dualfrequency retrievals are available in roughly half of all bins for the $817 \mathrm{~km}$ orbit and in two-thirds of the bins for the $450 \mathrm{~km}$ orbit. Usually, when multi-frequency observations are unavailable, it is because the reflectivity is so low that the W-band radar is the only one that is sensitive enough to make a detection. In these cases, the scattering particles are almost always small, in or near the Rayleigh scattering regime, and therefore all radar bands have similar reflectivities, which would limit the usefulness of multi-frequency retrievals in any case.

The main differences between the 450 and $817 \mathrm{~km}$ orbital scenarios are the decreased sensitivity and more significant NUBF at the $817 \mathrm{~km}$ orbit. The decreased sensitivity appears to have a fairly small effect on the total detection rate, as only about $3 \%$ of the total radar bins measured at the $450 \mathrm{~km}$ orbit are missing from the $817 \mathrm{~km}$ measurements. The decreased sensitivity affects the availability of triple-frequency measurements more severely: globally, the simultaneous availability of all three bands differs by a factor of 1.5 between the frequency bands, although this difference varies significantly by region and altitude level.
It appears that the main limitation of this configuration in capturing the three-dimensional structure of all detectable clouds is due to the footprint size and the resulting NUBF. Reducing the footprint size would require either an orbital altitude significantly lower than $450 \mathrm{~km}$ (undesirable from a mission lifetime standpoint) or a significantly larger antenna (with consequences to the overall cost of the mission). More practical solutions should be considered on the algorithmic side: NUBF can be mitigated by exploiting partially overlapped footprints and frequency dependence of the surface backscatter (approaches currently being tested in the GPM mission). In both regards, the data acquisition strategies adopted by this radar should be defined to deliver considerable information to support such algorithms (that is, to provide significant overlap for range and footprint sampling). For a general (albeit preliminary) assessment, one can see the error category 1 adopted in this paper as a particularly benign one: in these pixels, one can reasonably expect only a slight degradation in the uncertainties of retrieved quantities. Categories 2 and 3 span a wide range of situations, varying from recoverable to unrecoverable, and they should be studied in depth to maximize the science return. Category 4 is, in fact, beyond reach, but it is also not strictly dependent on the footprint size per se (rather depending on the overall detection threshold of each channel).

Besides multi-frequency techniques, cloud and precipitation radar retrievals can be enhanced by Doppler velocity measurements, dual-polarization techniques (such as the use of the linear depolarization ratio) and combining the radars with other instruments such as microwave radiometers, imaging spectrometers or lidars. Such instruments can be located on the same satellite or on other satellites flying in constellation. Indeed, the possibly increased availability of constellation flying opportunities was our main motivation for investigating the $817 \mathrm{~km}$ orbital scenario. In order to enable a reliable and comprehensive cost-benefit analysis of different mission options, future studies should assess the relative value of these techniques compared to multi-frequency radars. 


\section{Appendix: Derivation of the snowflake size distribution}

The NICAM microphysics model assumes that the snowflake PSD is (Tomita, 2008)

$N_{\mathrm{sc}}\left(D_{\mathrm{sc}}\right)=N_{0, \mathrm{~s}} \exp \left(-\Lambda_{\mathrm{s}} D_{\mathrm{sc}}\right)$,

and that the snow density is constant at $\rho_{\mathrm{sc}}$. As explained in Sect. 2.2.3, we assume that the snowflake mass distribution implied by Eq. (1) remains valid as we transition to snowflakes of variable density. The diameter $D_{\mathrm{sc}}$ of a constant-density snowflake is related to that of a variabledensity snowflake of equal mass, $D_{\mathrm{sv}}$, as

$m=\frac{\pi}{6} \rho_{\mathrm{sc}} D_{\mathrm{sc}}^{3}=\alpha D_{\mathrm{sv}}^{\beta}$.

Thus we get

$D_{\mathrm{sc}}=C D_{\mathrm{sv}}^{\beta / 3}$,

with the constant

$C=\left(\frac{6 \alpha}{\pi \rho_{\mathrm{sc}}}\right)^{1 / 3}$,

and by differentiating Eq. (3) with respect to $D_{\mathrm{sv}}$,

$\mathrm{d} D_{\mathrm{sc}}=\frac{C \beta}{3} D_{\mathrm{sv}}^{\beta / 3-1} \mathrm{~d} D_{\mathrm{sv}}$.
As the mass distributions are assumed to be equal, we require equivalence of the constant-density and variabledensity forms:

$N_{\text {sv }}\left(D_{\text {sv }}\right) \mathrm{d} D_{\text {sv }}=N_{\text {sc }}\left(D_{\text {sc }}\right) \mathrm{d} D_{\text {sc }}$.

By substituting Eqs. (1), (3) and (5) onto the right hand side, we get

$$
\begin{aligned}
& N_{\mathrm{sv}}\left(D_{\mathrm{sv}}\right) \mathrm{d} D_{\mathrm{sv}}=N_{0, \mathrm{~s}} \exp \left(-\Lambda_{s} D_{\mathrm{sc}}\right) \mathrm{d} D_{\mathrm{sc}} \\
& =N_{0, \mathrm{~s}} \exp \left(-C \Lambda_{s} D_{\mathrm{sv}}^{\beta / 3}\right) \frac{C \beta}{3} D^{\beta / 3-1} \mathrm{~d} D_{\mathrm{sv}},
\end{aligned}
$$

which is equivalent to Eq. (6), where we have dropped the subscript "sv" for brevity. 
Acknowledgements. We would like to thank three anonymous reviewers for their helpful and constructive comments. This research was supported in part by the National Aeronautics and Space Administration (NASA) Aerosol-Clouds-Ecosystem project. The research of J. Leinonen, M. D. Lebsock, S. Tanelli and K. Suzuki described in this publication was carried out at the Jet Propulsion Laboratory, California Institute of Technology, under contract with NASA.

Edited by: M. Kulie

\section{References}

Battaglia, A. and Tanelli, S.: DOMUS: DOppler MUltipleScattering Simulator, IEEE T. Geosci. Remote, 49, 442-450, doi:10.1109/TGRS.2010.2052818, 2011.

Battaglia, A., Tanelli, S., Kobayashi, S., Zrnic, D., Hogan, R. J., and Simmer, C.: Multiple-scattering in radar systems: a review, J. Quant. Spectrosc. Radiat. Transfer, 111, 917-947, doi:10.1016/j.jqsrt.2009.11.024, 2010.

Battaglia, A., Tanelli, S., Mroz, K., and Tridon, F.: Multiple scattering in observations of the GPM dual-frequency precipitation radar: Evidence and impact on retrievals, J. Geophys. Res.Atmos., 120, 4090-4101, doi:10.1002/2014JD022866, 2015.

Bodas-Salcedo, A., Webb, M. J., Bony, S., Chepfer, H., Dufresne, J.-L., Klein, S. A., Zhang, Y., Marchand, R., Haynes, J. M., Pincus, R., and John, V. A.: COSP: satellite simulation software for model assessment, B. Am. Meteorol. Soc., 92, 1023-1043, doi:10.1175/2011BAMS2856.1, 2011.

Fabry, F. and Szyrmer, W.: Modeling of the melting layer. Part II: Electromagnetic, J. Atmos. Sci., 56, 3593-3600, doi:10.1175/1520-0469(1999)056<3593:MOTMLP>2.0.CO;2, 1999.

Furukawa, K., Kojima, M., Miura, T., Hyakusoku, Y., Kai, H., Ishikiri, T., Iguchi, T., Hanado, H., Nakagawa, K. and Okumura, M.: The orbital checkout status of the dual-frequency precipitation radar on the global precipitation measurement core spacecraft, in: IEEE Geoscience and Remote Sensing Symposium, Quebec City, Canada, 13-18 July 2014, 3750-3753, doi:10.1109/IGARSS.2014.6947299, 2014.

Geer, A. J. and Baordo, F.: Improved scattering radiative transfer for frozen hydrometeors at microwave frequencies, Atmos. Meas. Tech., 7, 1839-1860, doi:10.5194/amt-7-1839-2014, 2014.

Hashino, T., Satoh, M., Hagihara, Y., Kubota, T., Matsui, T., Nasuno, T., and Okamoto, H.: Evaluating cloud microphysics from NICAM against CloudSat and CALIPSO, J. Geophys. Res.Atmos., 118, 7273-7292, doi:10.1002/jgrd.50564, 2013.

Haynes, J. M., L'Ecuyer, T. S., Stephens, G. L., Miller, S. D., Mitrescu, C., Wood, N. B., and Tanelli, S.: Rainfall retrieval over the ocean with spaceborne W-band radar, J. Geophys. Res., 114, D00A22, doi:10.1029/2008JD009973, 2009.

Heymsfield, A. J., Schmitt, C., and Bansemer, A.: Ice cloud particle size distributions and pressure-dependent terminal velocities from in situ observations at temperatures from $0^{\circ}$ to $-86^{\circ} \mathrm{C}$, J. Atmos. Sci., 70, 4123-4154, doi:10.1175/JAS-D-12-0124.1, 2013.

Hogan, R. and Battaglia, A.: Fast lidar and radar multiple-scattering models. Part II: Wide-angle scattering using the time-dependent two-stream approximation, J. Atmos. Sci., 65, 3636-3651, doi:10.1175/2008JAS2643.1, 2008.

Hou, A. Y., Kakar, R. K., Neeck, S., Azarbarzin, A. A., Kummerow, C. D., Kojima, M., Oki, R., Nakamura, K., and Iguchi, T.: The Global Precipitation Measurement (GPM) mission, B. Am. Meteorol. Soc., 95, 701-722, doi:10.1175/BAMS-D-1300164.1, 2014.

Hélière, A., Lefebvre, A., Wehr, T., Bézy, J.-L., and Durand, Y.: The EarthCARE mission: mission concept and lidar instrument pre-development, in: IEEE Geoscience and Remote Sensing Symposium, Barcelona, Spain, 23-28 July 2007, 4975-4978, doi:10.1109/IGARSS.2007.4423978, 2007.

Kneifel, S., Kulie, M. S., and Bennartz, R.: A triple frequency approach to retrieve microphysical snowfall parameters, J. Geophys. Res., 116, D11203, doi:10.1029/2010JD015430, 2011.

Kollias, P., Tanelli, S., Battaglia, A. and Tatarevich, A.: Evaluation of EarthCARE Cloud Profiling Radar Doppler velocity measurements in particle sedimentation regimes, J. Atmos. Oceanic Technol., 31, 366-386, doi:10.1175/JTECH-D-1100202.1, 2014.

Kulie, M. S., Hiley, M. J., Bennartz, R., Kneifel, S., and Tanelli, S.: Triple frequency radar reflectivity signatures of snow: observations and comparisons to theoretical ice particle scattering models, J. Appl. Meteorol. Clim., 53, 1080-1098, doi:10.1175/JAMC-D-13-066.1, 2014.

Kummerow, C., Simpson, J., Thiele, O., Barnes, W., Chang, A. T. C., Stocker, E., Adler, R. F., Hou, A., Kakar, R., Wentz, F., Ashcroft, P., Kozu, T., Hong, Y., Okamoto, K., Iguchi, T., Kuroiwa, H., Im, E., Haddad, Z., Huffman, G., Ferrier, B., Olson, W. S., Zipser, E., Smith, E. A., Wilheit, T. T., North, G., Khrisnamurti, T., and Nakamura, K.: The status of the Tropical Rainfall Measuring Mission (TRMM) after two years in orbit, J. Appl. Meteorol., 39, 1965-1982, doi:10.1175/1520-0450(2001)040<1965:TSOTTR>2.0.CO;2, 2000.

Lebsock, M. D. and L'Ecuyer, T. S.: The retrieval of warm rain from CloudSat, J. Geophys. Res., 116, D20209, doi:10.1029/2011JD016076, 2011.

Leinonen, J.: High-level interface to T-matrix scattering calculations: architecture, capabilities and limitations, Opt. Express, 22, 1655-1660, doi:10.1364/OE.22.001655, 2014.

Leinonen, J. and Moisseev, D.: What do triple-frequency radar signatures reveal about aggregate snowflakes?, J. Geophys. Res., 120, 229-239, doi:10.1002/2014JD022072, 2015.

Leinonen, J., Kneifel, S., Moisseev, D., Tyynelä, J., Tanelli, S., and Nousiainen, T.: Evidence of nonspheroidal behavior in millimeter-wavelength radar observations of snowfall, J. Geophys. Res., 117, D18205, doi:10.1029/2012JD017680, 2012.

Leon, D. C., Wang, Z., and Liu, D.: Climatology of drizzle in marine boundary layer clouds based on 1 year of data from CloudSat and Cloud-Aerosol Lidar and Infrared Pathfinder Satellite Observations (CALIPSO), J. Geophys. Res., 113, D00A14, doi:10.1029/2008JD009835, 2008.

Liu, G.: A database of microwave single-scattering properties for nonspherical ice particles, B. Am. Meteorol. Soc., 89, 15631570, doi:10.1175/2008BAMS2486.1, 2008.

Mace, G. G., Zhang, Q., Vaughan, M., Marchand, R., Stephens, G., Trepte, C., and Winker, D.: A description of hydrometeor layer occurrence statistics derived from the first year of merged 
Cloudsat and CALIPSO data, J. Geophys. Res., 114, D00A26, doi:10.1029/2007JD009755, 2009.

Marchand, R., Mace, G. G., Ackerman, T., and Stephens, G.: Hydrometeor detection using Cloudsat - an Earth-orbiting 94GHz cloud radar, J. Atmos. Oceanic Technol., 25, 519-533, doi:10.1175/2007JTECHA1006.1, 2008.

Miles, N. L., Verlinde, J., and Clothiaux, E. E.: Cloud droplet size distributions in low-level stratiform clouds, J. Atmos. Sci., 57, 295-311, doi:10.1175/15200469(2000)057<0295:CDSDIL>2.0.CO;2, 2000.

Mishchenko, M. I. and Travis, L. D.: Capabilities and limitations of a current FORTRAN implementation of the T-matrix method for randomly oriented, rotationally symmetric scatterers, J. Quant. Spectrosc. Ra., 60, 309-324, doi:10.1016/S00224073(98)00008-9, 1998.

Miyamoto, Y., Kajikawa, Y., Yoshida, R., Yamaura, T., Yashiro, H., and Tomita, H.: Deep moist atmospheric convection in a subkilometer global simulation, Geophys. Res. Lett., 40, 4922-4926, doi:10.1002/grl.50944, 2013.

Nowell, H., Liu, G., and Honeyager, R.: Modeling the microwave single-scattering properties of aggregate snowflakes, J. Geophys. Res. Atmos., 118, 7873-7885, doi:10.1002/jgrd.50620, 2013.

Petty, G. W. and Huang, W.: Microwave backscatter and extinction by soft ice spheres and complex snow aggregates, J. Atmos. Sci., 67, 769-787, doi:10.1175/2009JAS3146.1, 2010.

National Research Council: Earth Science and Applications from Space: National Imperatives for the Next Decade and Beyond, National Academies Press, Washington, DC, USA, 2007.

Ray, P. S.: Broadband complex refractive indices of ice and water, Appl. Optics, 11, 1836-1844, doi:10.1364/AO.11.001836, 1972.

Satoh, M., Matsuno, T., Tomita, H., Miura, H., Nasuno, T., and Iga, S.-I.: Nonhydrostatic icosahedral atmospheric model (NICAM) for global cloud resolving simulations, J. Comput. Phys., 227, 3486-3514, doi:10.1016/j.jcp.2007.02.006, 2008.

Satoh, M., Tomita, H., Yashiro, H., Miura, H., Kodama, C., Seiki, T., Noda, A. T., Yamada, Y., Goto, D., Sawada, M., Miyoshi, T., Niwa, Y., Hara, M., Ohno, T., Iga, S., Arakawa, T., Inoue, T., and Kubokawa, H.: The Non-hydrostatic Icosahedral Atmospheric Model: description and development, Prog. Earth Planet. Sci., 1, 18, doi:10.1186/s40645-014-0018-1, 2014.

Stephens, G. L., Vane, D. G., Tanelli, S., Im, E., Durden, S., Rokey, M., Reinke, D., Partain, P., Mace, G. G., Austin, R., L'Ecuyer, T., Haynes, J., Lebsock, M., Suzuki, K., Waliser, D., Wu, D., Kay, J., Gettelman, A., Wang, Z., and Marchand, R.: CloudSat mission: performance and early science after the first year of operation, J. Geophys. Res., 113, D00A18, doi:10.1029/2008JD009982, 2008.
Suzuki, K., Stephens, G. L., Van Den Heever, S. C., and Nakajima, T. Y.: Diagnosis of the warm rain process in cloudresolving models using joint CloudSat and MODIS observations, J. Atmos. Sci., 68, 2655-2670, doi:10.1175/JAS-D-1005026.1, 2011.

Tanelli, S., Durden, S. L., Im, E., Pak, K. S., Reinke, D. G., Partain, P. Haynes, J. M. and Marchand, R.T.: CloudSat's Cloud Profiling Radar After Two Years in Orbit: Performance, Calibration, and Processing, IEEE T. Geosci. Remote, 46, 3560-3573, doi:10.1109/TGRS.2008.2002030, 2008.

Tanelli, S., Durden, S. L., Im, E., Heymsfield, G. M., Racette, P., and Starr, D.O.: Next-generation spaceborne cloud profiling radars, in IEEE radar conference, 1-4, Pasadena, USA, doi:10.1109/RADAR.2009.4977116, 2009.

Thurai, M., Bringi, V. N., Szakáll, M., Mitra, S. K., Beard, K. V., and Borrmann, S.: Drop shapes and axis ratio distributions: comparison between 2D video disdrometer and windtunnel measurements, J. Atmos. Ocean. Tech., 26, 1427-1432, doi:10.1175/2009JTECHA1244.1, 2009.

Tomita, H.: New microphysical schemes with five and six categories by diagnostic generation of cloud ice, J. Meteorol. Soc. Jpn., 86A, 121-142, doi:10.2151/jmsj.86A.121, 2008.

Tomita, H. and Satoh, M.: A new dynamical framework of nonhydrostatic global model using the icosahedral grid, Fluid Dyn. Res., 34, 357-400, doi:10.1016/j.fluiddyn.2004.03.003, 2004.

Tyynelä, J., Leinonen, J., Moisseev, D., and Nousiainen, T.: Radar backscattering from snowflakes: comparison of fractal, aggregate and soft-spheroid models, J. Atmos. Ocean. Tech., 28, 13651372, doi:10.1175/JTECH-D-11-00004.1, 2011.

van de Hulst, H. C.: Light Scattering by Small Particles, John Wiley \& Sons, New York, USA, 1957.

Warren, S. G. and Brandt, R. E.: Optical constants of ice from the ultraviolet to the microwave: a revised compilation, J. Geophys. Res., 113, D14220, doi:10.1029/2007JD009744, 2008. 